\title{
Impacto da responsabilidade social sob a óptica empresarial do norte litoral de Portugal
}

Fecha de recepción: 03.06.2013

Fecha de aceptación: 19.12.2013

Valentin Alejandro

Martínez Fernández

Universidad de A Coruña

valejand@udc.es

Óscar Juanatey Boga Universidad de A Coruña oscarjb@udc.es

\section{Maria José da Silva}

\section{Faria}

Instituto Superior da Maia mfaria@docentes.ismai.pt

\section{Resumo}

A responsabilidade social surge na literatura a partir do século XIX e, desde então, tem ganho maior expressão, atenção e interesse por parte dos estudiosos, empresários e o público em geral. Em especial devido ao seu impacto. Assim, a responsabilidade social tem tido nas últimas décadas uma forte expansão que se tem traduzido na sua aplicabilidade estratégica no mundo dos negócios. Hoje os académicos e os empresários caminham lado a lado experimentando novas estratégias que incluem novas variáveis num estudo fomentado no aparecimento de novas formas de negócio e de actuação de redes sociais. Face a esta nova conjuntura é objectivo deste artigo verificar se existe impacto na adopção de práticas de responsabilidade social pelas empresas Maiatas e, em caso afirmativo, analisar se afectam positiva ou negativamente a imagem das empresas do norte litoral de Portugal. Este artigo está estruturado em duas secções. A primeira é composta por uma revisão de literatura sobre o tema, dando a conhecer os principais marcos conceptuais do tema em análise. A segunda secção é composta por um estudo empírico através de uma análise factorial multivariável que permite desencadear as primeiras conclusões sobre o impacto da responsabilidade social em Portugal, concretamente nas empresas objecto de estudo. Foi possível apurar com base no estudo que a prática da responsabilidade social cria impacto nas acções das empresas mas não o produz de forma significativa nos seus resultados económicos.

Palavras-chave: responsabilidade social, resultados, sustentabilidade, empresas, Maia 


\title{
The social responsibility impact under the Portuguese north litoral entrepre- neurship optic
}

\begin{abstract}
Abstrac
Social responsibility appears in the literature in the nineteenth century and since then it has gained greater expression, attention and interest by scholars, entrepreneurs and the general public. In particular, because of its impact. Thus, social responsibility has had, in the last decades, a strong expansion which has resulted in its applicability in business strategy. Today, academics and businessmen go hand in hand trying new strategies that include new variables in a study fostered by the emergence of new forms of business and social networking activity. Given this new situation, it is the purpose of this article to test if there is an impact on the adoption of CSR practices by companies in Maia and, if so, consider whether they positively or negatively affect the corporate image of Portugal north coast enterprises. This article is structured in two sections. The first one consists of a literature review on the topic, presenting the main theme of the conceptual frameworks for analysis. The second section consists of an empirical study using a factorial multivariate analysis that allows us to trigger the first conclusions on the impact of social responsibility in Portugal, particularly in the companies under study. It was found from the study that the practice of social responsibility creates an impact on the companies' shares but does not produce it significantly on their economic results.
\end{abstract}

Keywords: social responsibility, results, sustainability, companies, Maia

\section{El impacto de la responsabilidad social bajo la óptica empresarial en el litoral norte de Portugal}

\section{Resumen}

La responsabilidad social surge en la literatura del siglo XIX y desde entonces ha ganado una mayor expresión, atención e interés de los estudiosos, empresarios y público en general, debido a su impacto en particular. Por lo tanto, la responsabilidad social ha tenido en las últimas décadas una fuerte expansión que ha llevado a su aplicabilidad en la estrategia empresarial. Hoy, académicos y hombres de negocios van juntos tratando nuevas estrategias que incluyen nuevas variables en un estudio propiciado por la aparición de nuevas formas de actividad empresarial y por la creación de redes sociales. Ante esta nueva situación, el propósito de este artículo es comprobar si hay un impacto en la adopción de prácticas de responsabilidad social de las empresas de Maia y, en caso afirmativo, si afecta positiva 
o negativamente a la imagen corporativa de las empresas en el litoral norte de Portugal. Este artículo se estructura en dos secciones. La primera consiste en una revisión de la literatura sobre el tema, presentando el tema principal de los marcos conceptuales para el análisis. La segunda parte consiste en un estudio empírico que utiliza un análisis multivariado factorial que permite la activación de las primeras conclusiones sobre el impacto de la responsabilidad social en Portugal, sobre todo en las empresas objeto de estudio. Se encontró en el estudio que la práctica de la responsabilidad social crea impacto en las acciones de las empresas, pero no se produce de manera significativa en sus resultados económicos.

Palabras clave: resultados de responsabilidad social, la sostenibilidad, las empresas, Maia

\section{Introdução}

As primeiras discussões de responsabilidade social de que há registo não são recentes (Burke \& Logsdon, 1996; Windsor, 2001; Husted, 2003; Smith, 2003; Jamali \& Mirshak, 2007), manifestaram-se no ano de 1899 nos EUA. Na altura o debate centrava-se nos princípios da caridade e da custódia (Freeman \& Stoner, 1992). Mais tarde, em 1920, com a Grande Depressão, apareceu um novo princípio, o do zelo, que se focava na melhor utilização do dinheiro das empresas ${ }^{1} \mathrm{em}$ acções que beneficiassem a sociedade como um todo (Stoner \& Freeman, 1999).

Pouco a pouco as empresas que realizavam práticas sociais com base nos princípios da caridade, da custódia e do zelo começaram a perceber que se tornavam mais visíveis e mais atractivas à sociedade. Esta foi a primeira análise para que começassem a utilizar estes princípios com fins estratégicos. A responsabilidade social tornou-se variável estratégica dando origem a alterações nas formas de gestão empresarial e a condicionar a performance social empresarial a partir dos ganhos alcançados (Arlow \& Gannon (1982), Husted \& Allen (2000, 2001), Wartick \& Cochran (1985), Wood (1991) \& Swanson $(1995,1999))$.

Da leitura e percepção da importância da responsabilidade social para as empresas foi objectivo deste estudo analisar a existência, ou não, de impacto na adopção de

\footnotetext{
${ }^{1}$ Competia a essas empresas aumentar a riqueza da sociedade, caso elas ignorassem os problemas sociais, as consequências de tal atitude, seriam de carácter destrutivo a longo prazo (Stoner \& Freeman, 1999).
} 
práticas de responsabilidade social pelas empresas da região da Maia no norte de Portugal. É nesta região norte que Portugal apresenta um forte tecido empresarial, maioritariamente dominado por micro, pequenas e médias empresas (PME), essencialmente pertencentes ao sector secundário e terciário (INE, 2009). Assim o objecto de estudo, empresas Maiatas, é dominado por entidades públicas e privadas num universo de 380 empresas, seleccionadas aleatoriamente e que representam cerca de 38\% das empresas nacionais. A metodologia que foi empregue no estudo foi uma análise factorial multivariável. Esta análise foi realizada com base nos dados extraídos das respostas a um questionário, dirigido às empresas objecto do estudo e estruturado em três partes. A primeira parte incluía a identificação, a segunda a verificação (ou não) de práticas de responsabilidade social e, a terceira parte compreendia um exame dos impactos da responsabilidade social nessas empresas.

Fruto da análise das respostas foi possível apurar que a prática da responsabilidade social cria impacto nas acções das empresas nacionais, seja na criação de emprego, seja na imagem organizacional, mas não produz impacto significativo nos resultados económicos destas empresas.

\section{Marco teórico}

Existe uma literatura vasta quando analisada a importância da Responsabilidade Social para as empresas (Nicolau \& Simaens, 2008). Correspondendo a esta afirmação Burke \& Logsdon (1996) estudaram as formas através das quais a Responsabilidade Social pode criar benefícios estratégicos para uma empresa, enquanto Husted (2003) estudou a governabilidade das formas alternativas de a exercer e o seu impacto na performance financeira. Contudo, o impacto das diversas modalidades na gestão das organizações permanece por avaliar e é sobre este tema que vale a pena fazer uma reflexão (Nicolau \& Simaens, 2009; Hasnaoui \& Freeman, 2010, 2011).

Da prática da responsabilidade social resulta uma performance social empresarial que produz um resultado que, não deve ser separado dos económicos, ambientais e tão pouco se pode dizer que se trata de um único resultado (Faria, 2012). Em Portugal, os resultados económicos parecem ser mais importantes para a maioria das empresas e, quanto maiores melhor (Carvalho \& Monteiro, 2002).

Associado a estes resultados está o desempenho económico e a sua relação com a responsabilidade social, dado que cada vez menos se aceita que a riqueza favoreça 
apenas os interesses de alguns, devendo a mesma contribuir para o interesse colectivo (AECA, 2004). Podemos então dizer que a responsabilidade social decorre não apenas da consideração de critérios e desempenhos de cariz financeiro, mas de preceitos aferidores da postura ética, social e ambiental das sociedades, na medida em que existe a expectativa, por parte dos investidores, de obter resultados a longo prazo decorrentes de políticas socialmente responsáveis (Monteiro, 2005).

Se se tratar de empresas que, por tradição, executam práticas de responsabilidade social, os seus resultados parecem mais favorecidos aos olhos dos stakeholders e do ambiente circundante (Nicolau \& Simaens, 2008). No entanto, para que não haja abuso ou uma competição pouco clara entre empresas que praticam a responsabilidade social foi crescendo a normalização. No processo crescente de normalização as normas mais importante pertence à família ISO, tais como a ISO 9000, ISO 14000 e a ISO 26000 (Carvalho \& Monteiro, 2004). O objectivo desta e outra normalização social consiste em colocar uma barreira à falta de responsabilidade social, ética nos negócios e práticas de gestão abusivas, bem como, garantir uma uniformização na divulgação de informação socialmente responsável que uma empresa produz (Faria, 2012). Quer por força da normalização quer por força da competição de mercado, algumas empresas no país procuram melhorar os produtos oferecidos, incrementando-os (ou não) com produtos amigos do ambiente; utilizam a publicidade como meio de comunicação para transparecer uma imagem socialmente responsável (Oliveira e \& Chaves, 2013), bem como, os rótulos dos produtos $^{2}$, os mapas financeiros e outras demonstrações da informação económica e financeira da empresa (Faria, 2012). Actualmente podemos dizer que as páginas Web das empresas são um dos poderosos instrumentos para veicular informação sobre práticas de responsabilidade social (Moral, Poyatos \& Jurado, 2010). Estas incluem informação qualitativa e quantitativa que pretende potenciar o consumo associado à marca ou ao produto. Em 2000 num estudo relativo às atitudes dos consumidores europeus, $70 \%$ consideravam importante as práticas de responsabilidade social, aquando do momento da decisão sobre a compra de um produto; $44 \%$ dos consumidores diziam-se dispostos a pagar mais por um produto oriundo de uma organização com práticas socialmente responsáveis (Oliveira e \& Chaves, 2013). O interesse num produto que espelha responsabilidade social depende de

\footnotetext{
${ }^{2}$ A rotulagem pode assumir diferentes formas mas em qualquer uma delas produzem impacto quer económico quer social (Manzini \& Vezzoli, 2005). Como a rotulagem é diferente de produto para produto foi criada legislação para a homogeneizar. Este processo de homogeneização foi lento e crescente e fez emergir um conjunto significativo de símbolos, imagens e frases (Harrington \& Knight, 2001) diante da necessidade e exigência do consumidor (Kazazian, 2005, 2005_a).
} 
diversos factores entre eles os elementos de uma sociedade. Atendendo à sua natureza, função e ligação com a comunidade é possível identificar um conjunto de acções, que cada um desses elementos pode empreender, para tornar os produtos e a sociedade mais responsáveis socialmente. A título de exemplo escolheram-se apenas alguns desses elementos e acções conforme se pode observar resumidamente no quadro 1 .

\section{Quadro 1 \\ Acções de Responsabilidade Social na sociedade}

\begin{tabular}{|c|c|}
\hline $\begin{array}{c}\text { Elementos da } \\
\text { sociedade }\end{array}$ & Responsabilidade Social da empresa \\
\hline Empregados & $\begin{array}{l}\text { Proporcionar condições laborais adequadas (Cowper-Smith \& Grosbois, 2011); } \\
\text { Efectuar avaliações contínuas de modo a verificar ou não a necessidade de } \\
\text { outplacement (Uccello, 2009); } \\
\text { Verificar periodicamente o grau de satisfação com a conduta social da empresa } \\
\text { (Nascimento, 2010; Tsuji \& Tsuji, 2010); } \\
\text { Ajustar os salários de acordo com a função e criar mecanismos de trabalho, por } \\
\text { incentivos (Nascimento, 2010); } \\
\text { Verificar o impacto das suas práticas sociais no nível de produtividade (Nascimento, } \\
2010 \text { ). }\end{array}$ \\
\hline Accionistas & \begin{tabular}{|l|} 
Contribuir na repartição de lucros (Dalton \& Cosier, 1982); \\
Melhorar a imagem institucional (Logsdon \& Yuthas, 1997).
\end{tabular} \\
\hline $\begin{array}{r}\text { Forn } \\
\text { distr }\end{array}$ & $\begin{array}{l}\text { Boa relação com os fornecedores e distribuidores (Ribeiro, Giuliani \& Corrêa, 2006); } \\
\text { Verificar o cumprimento de prazos (Ribeiro, Giuliani \& Corrêa, 2006); } \\
\text { Atender às qualidades das matérias/produtos (Ribeiro, Giuliani \& Corrêa, 2006); } \\
\text { Verificar qual a proveniência dos mesmos (Ribeiro, Giuliani \& Corrêa, 2006); } \\
\text { Controlar as formas de negociação face a materiais escassos (Ribeiro, Giuliani \& } \\
\text { Corrêa, 2006). }\end{array}$ \\
\hline Consumidores & $\begin{array}{l}\text { Trabalhar com o objectivo de satisfazer as suas necessidades (Ackerman, 1973); } \\
\text { Atender às campanhas publicitárias como apelo à sua ligação à empresa (Shwatz } \\
\text { \& Carrol, 2003); } \\
\text { Atender à qualidade e garantia dos produtos (Shwatz \& Carrol, 2007); } \\
\text { Fornecer um atendimento e serviços pós vendas adequados às necessidades (Shwatz } \\
\text { \& Carrol, 2007); } \\
\text { Sensibilizar os consumidores para o seu produto salientando características reais } \\
\text { face à concorrência (Shwatz \& Carrol, 2008); } \\
\text { Difundir uma imagem preocupada e sensível aos elementos sociais da comunidade } \\
\text { em que está inserida (Campos, Moreno \& Lemme, 2007; Amazeen, 2011). }\end{array}$ \\
\hline Comunidade & $\begin{array}{l}\text { Mostrar as suas actividades de ajuda social (Carrol \& Buchholtz, 1999); } \\
\text { Dar atenção às reivindicações da comunidade local (Carrol \& Buchholtz, 1999); } \\
\text { Desenvolver a colectividade com preocupação pelo bem-estar social e verificar } \\
\text { como tal se reverte na lucratividade da empresa (Manzini, Vezzoli \& Clark, 2005); } \\
\text { "Esconder" a elevada lucratividade à custa de apoio ao equilíbrio social (Manzini, } \\
\text { Vezzoli \& Clark, 2005). }\end{array}$ \\
\hline
\end{tabular}

Fonte: Elaboração própria. 
Como os interesses são múltiplos e a prática da responsabilidade social pode ainda ser mais variada então Martínez, Boga, Orosa \& Campo $(2005,5)$ defendem que "se se parte da ideia que a responsabilidade social das empresas, em linhas gerais, consiste num conjunto de princípios, políticas, programas e sistemas de gestão nos âmbitos económico, social e meio ambiental dirigido a incorporar na estratégia empresarial valores e expectativas dos diversos públicos internos e externos com o objectivo de incrementar o valor da marca e a reputação à empresa..." Igualmente referem os autores no âmbito da comunicação da informação de responsabilidade social que: "a transparência informativa no respeito pelos resultados, dá à comunicação uma ferramenta essencial de gestão que requer pertinentes estratégias conducentes a um maior nível de eficiência e criação de adequadas respostas a tendências emergentes, que em maior ou menor medida, possam incidir de maneira negativa na empresa" (Martínez, Boga, Orosa \& Campo, 2005, 6).

Logo a comunicação empresarial ao nível da responsabilidade social deixa de ser um elemento importante para se tornar num factor chave de sucesso, para que, o ambiente circundante possa favorecer a empresa, ser beneficiado por esta e ainda contribuir para que a sua mensagem/actuação possa ser seguida por outros.

\section{Comunicação da responsabilidade social}

A comunicação é uma chave de sociabilização (Pérez, 2012), cujo paralelo é muito variável e está directamente relacionado com a necessidade do homem e com a nova planificação das empresas que não têm que ter estratégia necessariamente mas, viver estrategicamente (Pérez, 2012). Assim, referem Martínez, Boga, Orosa \& Campo $(2005,2)$ "a responsabilidade social das empresas implica o reconhecimento destas como uma instituição que além de ter responsabilidade e obrigações legítimas perante os seus proprietários será também responsável pelos impactos sociais e ambientais das suas actividades".

Os impactos causados podem ser visíveis e invisíveis. Independentemente da sua natureza e extensão é importante a sua comunicação. A forma pela qual esta é realizada é diferente de empresa para empresa, ou de país para país por razões de tradição, desenvolvimento dos mercados, interesse dos stakeholders, etc. Não há no entanto registo ou prova de formas melhores ou piores mas de formas mais ou menos eficazes e mais ou menos antiquadas. Os Mass Média no seu todo tem as melhores formas, os panfletos e as imagens nos pontos de venda constituem as mais eficazes e as redes sociais as mais actuais (Serra, 2008). Não esquecer no 
entanto que as formas tradicionais de comunicação da informação económico-financeira: balanço, demonstração dos resultados, balanço social e outros mapas contabilísticos são igualmente um meio de divulgação forte no âmbito da comunicação empresarial (Faria, 2012).

Regra geral os mapas contabilísticos de divulgação social são voluntários, isto tem conduzido ao chamado mapa de informação solicitado (Laan, 2009). Este mapa contabilístico é redigido com base em respostas de questionários (Laan, 2009), com uma natureza mais qualitativa face à quantitativa (Baxi \& Ray, 2009). Este relato voluntário de informação faz com que as empresas decidam o que, quando, e como informar (Jonas \& Jones, 2010, 2011; Kaplan \& Norton, 2004). Este nível abstracto pode ir de encontro às necessidades dos stakeholders mas, reduz sensivelmente a transparencia e o apoio para a tomada de decisões (Laan, 2009; Kavitha \& Anita, 2011). Neste âmbito a contabilidade tem o compromisso de ajudar (Gilbert, Rasche \& Waddock, 2011).

As normas de contabilidade que assistem a divulgação da responsabilidade social dividem-se entre as que incluem princípios orientadores, certificação, relato e normas de processo (Gilbert, Rasche, Waddock, 2011) e, os códigos de conduta (Ehrgott, Reimann, Kaufmann \& Carter, 2011; Fassin \& Buelens, 2011). Logo de acordo com a normalização o veículo mais adequado para o relato socialmente responsável é o relatório e contas de uma empresa. A divulgação de informação no relatório de contas anual é muito pequena, já o relato voluntário inclui múltipla informação mas a sua quantidade compromete a qualidade e a comparabilidade espacial e temporal da informação (Dhaliwal, Li, Tsang \& Yang, 2011). É importante a sua existência devido a: argumentos que defendem que a divulgação de informação tem um efeito positivo na performance dos mercados, e há razões que advogam que a gestão da empresa ganha legitimidade, há ainda indícios de uma relação contactual entre as empresas e a sociedade que revela que o relato voluntário representa o reconhecimento contabilístico moral da empresa (Clarke \& Gibson-Sweet, 1999). Além destes o principal benefício associado ao relato voluntário é a redução do custo de capital. Esta situação tem implicações directas para as empresas, para os investidores e implicitamente para os normalizadores (Dhaliwal, Li, Tsang \& Yang, 2012). O relato voluntário é realizado com maior expressão no relatório do director ou na carta do presidente como forma de legitimar as acções socialmente responsáveis realizadas pelas empresas. 
$\mathrm{Na}$ actualidade a informação de responsabilidade social que é relatada aparece misturada com a informação financeira (Faria, 2012). No relatório e contas o relato contabilístico de responsabilidade social que é realizado faz referência entre outros aos seguintes aspectos: capital humano/informação sobre os empregados; ambiente; envolvimento comunitário; contribuição de produtos e serviços, cliente e consumidor. Esta informação aparece em conjunto, sem permitir perceber as componentes e os valores que pertencem a uma ou outra rubrica. Os blocos informativos que aparecem no puzzle são de tal maneira necessários que observando a totalidade do relato deve-se proceder a uma reclassificação quer do activo quer do passivo e da situação líquida (Guse, Calu, Avram, Calu \& Popescu, 2010). Os autores propõem uma reclassificação dos activos nas seguintes tipologias: activos naturais, activos neutros e activos poluentes. Tendo presente que os activos naturais não são objecto de medida monetária é apropriado mantê-los de acordo com as técnicas qualitativas de relato da responsabilidade social (Guse, Calu, Avram, Calu \& Popescu, 2010). Nos restantes casos o problema do modelo de medida assenta na dificuldade de medir custos e benefícios, razão pela qual se utilizam rácios, indicadores e outras medidas para determinar o impacto destas externalidades (Guse, Calu, Avram, Calu \& Popescu, 2010; Gates \& Germain, 2010).

Geralmente a contabilidade tradicional das empresas não reconhece o impacto de determinados activos ambientais e implicitamente dá ideia que não é capaz de informar sobre a sua sustentabilidade. O relato voluntário poderia ser uma solução que aparentemente o é, mas é limitada ao hiato contabilístico e à ausência de critérios uniformes de auditoria (Guse, Calu, Avram, Calu \& Popescu, 2010).

Assim, o problema do relato da responsabilidade social empresarial é providenciar pouca evidência contabilística (Solomon e Lewis, 2002). Não é de surpreender a relutância para o detalhe na informação de domínio público e o desinteresse no relato voluntário (Solomon \& Lewis, 2002). Para romper com esta situação de vazio informacional financeiro é necessário uma revolução. Só assim o relato passa a alavancar novas vantagens competitivas que passam por pensar e actuar verde (Faria, 2012; Damak-Ayadi, 2009). Nem o avanço japonês no âmbito da contabilidade ambiental e na divulgação de informação social está a conseguir ultrapassar este problema (Cortez \& Penacerrada, 2010). O relato de responsabilidade social verifica combinação de medidas financeiras e não financeiras, rácios de sustentabilidade e outros cuja prática dificulta o relato contabilístico da responsabilidade social nas contas anuais (Faria, 2012; Farneti \& Guthrie, 2007, 2008). 
Há um caminho muito longo a percorrer para que a divulgação económica e financeira insira todos os elementos considerados de responsabilidade social.

\section{As empresas portuguesas diante da comunicação de responsabilidade social}

Em Portugal a generalidade das empresas existentes são micro, pequenas e médias empresas. Poderá ser devido ao seu tamanho que as pequenas e médias empresas - PME geralmente não dão a conhecer a sua actividade de responsabilidade social empresarial. Em certos casos para não dar a impressão de estar a "colocar medalhas" ou de utilizar a acção social como uma "cínica" estratégia de marketing. Algumas PME pensam que fazer publicidade da responsabilidade social é um acto exclusivamente de grandes empresas. Para outras a responsabilidade social é algo tão completamente natural que nunca se lhes ocorreria falar sobre isso. Em todo o caso podemos dizer que com base nos estudos realizados, as grandes empresas são melhores em termos de resultados de responsabilidade social, mas são as empresas mais pequenas que têm na realidade um impacto maior, já que se encontram sempre mais próximas das comunidades circundantes e as servem melhor o que implica por completo a inclusão da responsabilidade social na sua prática habitual e nas suas contas (Faria, 2012).

Podemos dizer que a responsabilidade social e a sua comunicação fazem parte de um conjunto de gastos que uma empresa faz para garantir a sua continuidade ao longo do tempo (Haider, 2010). Este conjunto de gastos faz parte de acções como:

- Proporcionar continuamente a formação ao longo do tempo;

- A promoção da igualdade em termos de remuneração;

- A manifesta preocupação com o emprego e a segurança social;

- Reduzir os gastos energéticos;

- Eliminar os excessos de resíduos;

- Reduzir os custos com as matérias-primas;

- Etc.

Todas estas acções conduzem as empresas a fazer uma comunicação baseada em três R's, de maneira a transmitir uma visão mais responsável (Farias, 2004):

1. Mais racional - mais informativa e rigorosa.

2. Mais razoável - atenção às promessas exageradas com relação a afirmações pouco verdadeiras. 
3. Mais relevante - mais pertinente e mais eficaz.

Em termos práticos em Portugal quando se faz uma estratégia integrada de comunicação é necessário questionar a sua pertinência, avaliar os seus impactos, integrar as preocupações sociais e ambientais e implementar estratégias de actuação e comunicação claras e directas. A importância deste tema é tão grande e actual que se formam fóruns nacionais entre as empresas e as universidades e entre as empresas e os empresários nacionais e estrangeiros para estudar os trajectos nacionais diante da responsabilidade social (Gonçalves \& Ribeiro, 2011). Destes fóruns além de se preconizar em novas estratégias, alinhar pontos de vista e conseguir melhorar a visão e percepção das acções de responsabilidade social esperam-se contributos muito além dos financeiros para levar os empresários portugueses a actuarem na dura modernidade dos tempos. Até ao momento as contribuições de fóruns e de outras investigações centram-se na comunicação da responsabilidade social e nas suas formas de actuação visíveis pela sociedade (Gonçalves \& Ribeiro, 2011). Resulta destes fóruns que a Responsabilidade Social atribui à contabilidade o objectivo de tornar pública a informação e as acções empreendidas pelas empresas (Torres, 2002). Hoje, a contabilidade tem entre muitas outras funções o dever de utilizar a responsabilidade social como ferramenta de gestão estratégica das suas acções. Nos novos modelos de gestão a informação contabilística é uma peça chave para a tomada de decisão sustentável em conformidade com a estrutura da empresa. Conforme refere Brookson (2003), a contabilidade de gestão, a contabilidade analítica e a contabilidade social, para além da contabilidade tradicional apoiam a prática e a divulgação da Responsabilidade Social ainda que as dificuldades de mensuração, reconhecimento e divulgação sejam elevadas. Para contornar estes problemas vão surgindo mapas, relatórios e indicadores adicionais às contas anuais (Bansal \& Sharma, 2006). Um deles é o balanço social que se posiciona como uma alternativa seguida por muitas empresas nacionais. Tem crescido a sua utilização e a sua legislação, não só por se tratar de uma forma mais prática de ultrapassar alguns dos problemas de registo e divulgação elencados, como por através do balanço social se demonstrar publicamente um conjunto de informações sobre projectos e acções sociais encetadas pelas empresas e dirigidas aos empregadores, investidores, accionistas e à comunidade em geral (Tinoco, 2001).

A divulgação das práticas de responsabilidade social através do balanço social dá a conhecer situações sustentáveis que nada têm a ver com o desenvolvimento desenfreado mas com um crescimento com calma, sustentado e com um olhar ético e solidário. Assim a responsabilidade social como conceito e prática vertidas na 
sua divulgação devem ser mais fortes e mais visíveis em Portugal, para que haja um maior impacto nas empresas, nos stakeholders e na forma como o mundo vê as nossas empresas (Faria, 2012).

\section{Análise empírica}

Com base na bibliografia citada constata-se que a maioria das empresas não executa ou é muito pobre na divulgação de informação de responsabilidade social, e assim, torna-se mais difícil de avaliar o seu impacto nas empresas. Em Portugal, a falta de divulgação de informação deve-se às principais dificuldades: medida, reconhecimento, identificação e divulgação. Com base nestas dificuldades foi realizado um questionário a um universo de entidades públicas e privadas, com o objectivo de apurar a congruência entre as conclusões nacionais apuradas na recensão bibliográfica nos últimos congressos de contabilidade realizados em Portugal e nos periódicos nacionais de maior referência científica (conforme quadro 2) e, a realidade das empresas portuguesas do concelho da Maia e arredores.

\section{Quadro 2}

Congressos de contabilidade e periódicos de contabilidade consultados (período de 2000 até 2012)

\begin{tabular}{|c|c|c|c|}
\hline $\begin{array}{c}\text { Temas de } \\
\text { responsabilidade } \\
\text { social procurados }\end{array}$ & $\begin{array}{l}\text { Congressos de } \\
\text { Contabilidade }\end{array}$ & $\begin{array}{l}\text { Periódicos } \\
\text { Nacionais }\end{array}$ & Principais autores consultados \\
\hline Capital Humano & 19 & 12 & $\begin{array}{l}\text { Moreira \& Pereira (2002) } \\
\text { Oliveira et al. (2002) } \\
\text { Carvalho (2002) } \\
\text { Rodrígues (2002) } \\
\text { Pargotto (2002) } \\
\text { Duarte (2002) } \\
\text { Pólo \& Vasquez (2004) } \\
\text { Beuren \& Colauto (2004) } \\
\text { Macagnan (2004) } \\
\text { Machado \& Sousa (2004) } \\
\text { Mancera (2004) } \\
\text { Duarte \& Sarmento_a (2004) } \\
\text { Colauto \& Lamounier (2006) } \\
\text { Greceanu (2006) } \\
\text { Gil, Arnosti \& Neumann (2006) } \\
\text { Conde \& Alonso (2008) } \\
\text { Carvalho, Rodrigues \& Ferreira (2008) } \\
\text { Crespo \& Bandeira (2008) } \\
\text { Marques (2008) }\end{array}$ \\
\hline
\end{tabular}




\begin{tabular}{|c|c|c|c|}
\hline & & & $\begin{array}{l}\text { Colauto \& Avelino (2008) } \\
\text { Antunes, Arnosti \& Neumann (2008) } \\
\text { Ferreira, Branco \& Moreira (2008) } \\
\text { Silva, Rodrigues, \& Dueñas (2011) } \\
\text { Silva, Colauto, Ferreira, \& Caíres (2011) } \\
\text { Anjos, \& Carvalho (2011) } \\
\text { Colauto, Cunha, Avelino \& Oliveira (2011) } \\
\text { Ribeiro, \& Riccio (2011) } \\
\text { Teixeira, Marques \& Petri-Dr (2011) } \\
\text { Graça, Ramos, \& Bandeira (2011) } \\
\text { Cavalcanti, Echternacht, Filho, \& Castro } \\
\text { (2011) } \\
\text { Silva, Rodrigues, \& Dueñas_a (2011) } \\
\text { Oliveira (2011) } \\
\text { Silva \& Ensslin (2011) }\end{array}$ \\
\hline Matérias Ambientais & 29 & 1 & $\begin{array}{l}\text { Pereira et al. (2002, 16) } \\
\text { Carvalho \& Monteiro (2002, 23-24) } \\
\text { Pargotto (2002, 12-13) } \\
\text { Becke (2004, 18) } \\
\text { Monteiro (2004, 12) } \\
\text { Mancera (2004, 12) } \\
\text { Eugénio (2004, 6) } \\
\text { Gilet (2004, 4-10) } \\
\text { Mayor \& Aléman (2004,1-8) } \\
\text { Santos (2004, 3-4) } \\
\text { Pimentel et al. (2004, 7) } \\
\text { Duarte \& Sarmento (2004, 14) } \\
\text { Ribeiro, Giuliani \& Corrêa (2006) } \\
\text { Bansal \& Sharma (2006) } \\
\text { Mayor (2006) } \\
\text { Borba, Rover \& Murcia (2006) } \\
\text { Jalón, Monedero \& Martín (2006) } \\
\text { Lima, Castro \& Echternacht (2006) } \\
\text { Morais \& Benito (2006) } \\
\text { Eugénio (2006) } \\
\text { Monteiro (2006) } \\
\text { Ansótegui \& Estrada (2006) } \\
\text { Abade, Aquino \& Ribeiro (2008) } \\
\text { Cordovil (2008) } \\
\text { Limongi, Kremer, Casagrande, Pfitscher \& } \\
\text { Nunes (2008) } \\
\text { Dias (2008) } \\
\text { Pinheiro, Angotti \& Moreira (2008) } \\
\text { Paiva, Laffin \& Alberton (2008) } \\
\text { Barros, Branco \& Delgado (2008) } \\
\text { Gallon, Vireira, Pfitscher, Limongi, } \\
\text { Leonardo \& Marian (2008) } \\
\text { Paula (2008) } \\
\text { Carvalho, Quirós \& Almeida (2008) }\end{array}$ \\
\hline
\end{tabular}




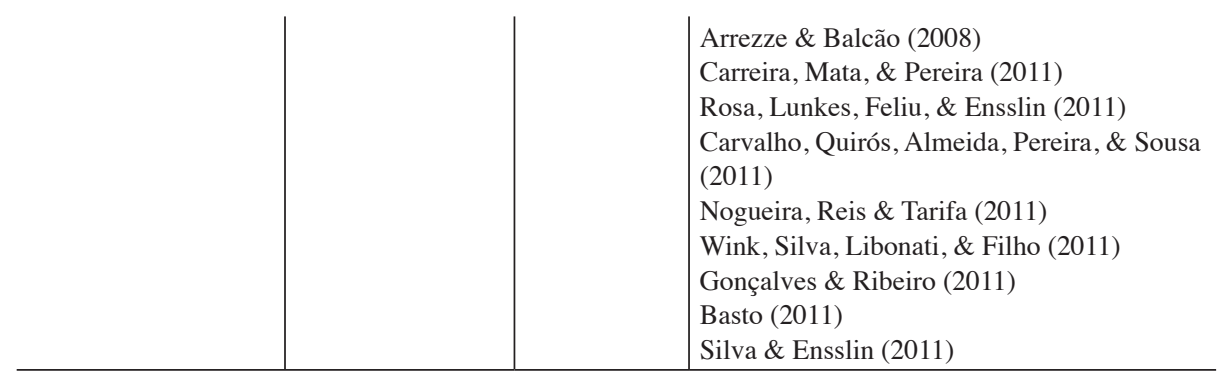

Fonte: Adaptado de Faria, 2012.

O interesse de efectuar o questionário residiu não só na verificação dos resultados nacionais a uma cidade portuguesa em particular, mas também, procurar justificações para a dificuldade no relato contabilístico do capital humano e matérias ambientais em particular e a comunicação da informação de responsabilidade social em geral. Nesse sentido, pretendeu-se com o questionário apurar quais as dificuldades que justificam a ausência de divulgação de informação contabilística sobre capital humano e matérias ambientais, quais as formas de divulgação da informação de responsabilidade social, verificação da sua existência independentemente da sua prática e uso estratégico e, a suficiência (ou insuficiência) normativa do relato social.

A região alvo do questionário situa-se no norte de Portugal, e pertence ao distrito do Porto. O território de estudo foi o concelho da Maia com uma área geográfica de $83,2 \mathrm{Km}^{2}$ distribuídos uniformemente ao longo de $6 \mathrm{~km}$ a norte do Porto com 17 freguesias e um total de 120.000 habitantes. É opinião pessoal que este concelho reúne as condições ideais para realizar este estudo, principalmente por ter uma concentração empresarial elevada, e por apresentar numa pequena área uma grande diversidade de negócios. O facto de ter sido escolhida uma área no norte de Portugal e não no Centro ou Sul do país está relacionado com o facto de nesta região se monopolizar efeitos sociais considerados desejáveis para as conclusões que se pretendem retirar com este estudo. As empresas que foram seleccionadas para envio do questionário foram escolhidas em termos de ramos de actividade, estrutura organizacional, tamanho, volume de negócios, resultados, etc. de acordo com um plano amostral proporcional e coincidente. Igualmente foi tido em consideração o facto de possuírem departamento de relações públicas, comunicação, contabilidade, e outros aspectos importantes no âmbito social, ambiental e humano. 
Do conjunto global de empresas que responderam ao questionário, enviado por e-mail e efectuado através de visitas entre os meses de Julho, Agosto e Setembro de 2011, por meio dos administradores, consultores, gerentes, contabilistas, técnicos superiores da área financeira, técnicos especialistas, operários e outros elementos dessas empresas, responderam mais de metade. O questionário realizado foi estruturado em quatro partes. A primeira referente à identificação para enquadramento da actividade da empresa e da pessoa que respondeu ao questionário. A segunda referente à estrutura organizacional dando conhecimento do tamanho e departamentos que constituem a empresa. A terceira parte questiona sobre a RSE, averiguando a atitude da empresa face à comunicação, uso estratégico e prática da responsabilidade social. A quarta parte refere-se à informação contabilística de capital humano e matérias ambientais que é ou não divulgada pelas empresas.

Das empresas que responderam (380) foi possível verificar que 370 são privadas e 10 são públicas. No conjunto de empresas privadas cerca de $51 \%$ são micro empresas, $20 \%$ são pequenas empresas, $7 \%$ médias e $22 \%$ correspondem a grandes empresas.

O primeiro passo consistiu, num total de 239 indicadores que constituem uma base de dados inicial (tantos quantos a questões do questionário), verificar a distribuição dos valores por cada um destes indicadores e identificar os dados omitidos. Estes critérios têm por objectivo o cumprimento dos pressupostos teóricos para a elaboração das escalas de medida através da análise factorial, ou seja, a normalidade dos dados e a homogeneidade da variância (Santos \& Ramos, 2006, 139). Este pré processamento de dados com técnicas de Data Mining consistiu em duas fases: selecção e filtragem. A fase de selecção permitiu eliminar os atributos que apresentam uma percentagem elevada de dados omitidos (superior a $8 \%$ ) tendo em consideração o erro amostral máximo admissível de 5\%.

Posteriormente e com base na análise de distribuição de cada um dos atributos foi possível proceder ao filtro e obter a base de dados final (RSE final). Assim foi possível definir as quatro dimensões da responsabilidade social empresarial sobre as quais incidirá a análise dos instrumentos de medida e respectivas escalas.

\section{Medição do grau de satisfação relativamente ao impacto económico na sociedade}

Os aspectos que foram considerados para analisar o impacto económico na sociedade e a satisfação desse impacto tiveram em consideração três estudos. O pri- 
meiro da Forrester Consulting de Outubro de 2007 onde a observação do impacto económico da actividade da Microsoft considerou quatro variáveis associadas à responsabilidade social:

- Custos

- Benefícios

- Riscos

- Flexibilidade

O segundo estudo considerou o Livro Verde para a RSE da Comissão Europeia onde está consagrado o modelo de gestão baseado no triple bottom line, ou 3 P's, onde cada P considera o foco económico (profit), social (people) e ambiental (planet).

O terceiro estudo considerou o parecer da iniciativa sobre a responsabilidade social das empresas, (Aprovado no Plenário de 17 de Janeiro de 2003), no qual as variáveis seleccionadas para estudo constam do referido relatório.

Considerando a semelhança e dissemelhança de variáveis entre os diferentes estudos, estas, conduziram para a escolha de quatro indicadores que pareceram adequados ao estudo do grau de satisfação do impacto económico das empresas da Maia.

No quadro 3 apresentam-se os 4 indicadores que integram a escala de medida do grau de satisfação relativamente ao impacto económico por parte das empresas que constituem a amostra na sociedade (IMPeco).

\section{Quadro 3}

Escala de medida da satisfação relativamente ao impacto económico (IMPeco)

\begin{tabular}{l}
\hline \multicolumn{1}{c}{ Descrição } \\
\hline 3.2.1 - Criação de emprego \\
\hline 3.2.2 - Criação de riqueza \\
\hline 3.2.3 - Desempenho da empresa na responsabilidade social \\
\hline 3.2.4 - Imagem organizacional
\end{tabular}

Fonte: Elaboração própria. 
Medição dos critérios que influenciam a adopção da responsabilidade social

Dada a inexistência de trabalhos que mensurem os critérios de adopção da responsabilidade social das empresas de forma rigorosa, procedeu-se à elaboração de uma escala de medida adequada aos objectivos da presente investigação.

A falta de trabalhos conduziu ao levantamento de indicadores que pudessem medir a RS. Assim, com base na bibliografia consultada foram identificados indicadores. Os principais estudos consultados para identificação dos indicadores foram:

- Diagnóstico de identificação de práticas de responsabilidade social nas PME (publicação ser PME um projecto do Ministério do Trabalho e da Segurança Social-MTSS). Fonte: http://www.shc.hu

- Responsabilidade social das empresas: um pouco de história e algumas reflexões, revista FAE, $n^{\circ}$ 9, Setembro de 2004, pp. 36-38

- Qualidade de vida no trabalho: origem, evolução e perspectivas, cadernos de pesquisa em administração, São Paulo, Vol. 8, No 1, Janeiro/Março, 2001.

Considerando a revisão de literatura foram escolhidos 11 indicadores que pareceram suficientemente abrangentes para verificar a influência da adopção da responsabilidade social nas empresas maiatas.

No quadro apresentam-se os 11 indicadores que integram a escala de medida dos critérios de adopção da responsabilidade social por parte das empresas que constituem a amostra (APArse). 


\section{Quadro 4}

Escala de medida da adopção da responsabilidade social (APArse)

\begin{tabular}{l}
\hline \multicolumn{1}{c}{ Descrição } \\
\hline 3.3.1 - Crescimento económico \\
\hline 3.3.2 - Aparecimento dos direitos humanos \\
\hline 3.3.3 - Emergência da certificação de qualidade \\
\hline 3.3.4 - Normalização de responsabilidade social \\
\hline 3.3.6 - Exigesencidade do relato da responsal \\
\hline 3.3.7 - Concessãa de benefícios fiscais \\
\hline 3.3.8 - Aparecimento de instituições sociais \\
\hline 3.3.10 - Apoio da igreja e da religião \\
\hline 3.3 .11 - Apoio dos sindicatos e outras instituições similares \\
\hline
\end{tabular}

Fonte: Elaboração própria.

Medição do impacto da comunicação da responsabilidade social para as empresas

Analisado o grau de satisfação relativamente ao impacto económico e a adopção das práticas de responsabilidade social era importante verificar o impacto que a comunicação da RS pode ter no meio circundante. Os estudos de Ribeiro e Lisboa (1999), Pandey (2005), Schadewitz \& Niskala (2010) e outros permitem demonstrar a quantidade de estudos em torno desta questão. Destes estudos verificou-se existirem variáveis centrais que funcionam estrategicamente na comunicação da responsabilidade social: marketing tradicional, filantropia, voluntariado, etc. Outras variáveis conexas têm também efeitos estratégicos. Dessas variáveis foram escolhidas as que podiam potenciar ou afundar uma estratégia de responsabilidade social. Nesse sentido seleccionaram-se 10 indicadores.

No quadro apresentam-se os 10 indicadores que integram a escala de medida da função estratégica da comunicação da responsabilidade social para as empresas que constituem a amostra (FUNcom). 


\section{Quadro 5}

\section{Escala de medida da função estratégica da comunicação da responsabilidade social (FUNcom)}

\begin{tabular}{l}
\hline \multicolumn{1}{c}{ Descrição } \\
\hline 3.12.1 - Aumento da visibilidade da imagem da empresa \\
\hline 3.12.2 - Aumento do valor da marca \\
\hline 3.12.3 - Aumento do desempenho organizacional \\
\hline 3.12.4 - Maior formação de lucros \\
\hline 3.12.5 - Associação prioritária dos objectivos organizacionais às causas sociais e não à formação de lucros \\
\hline 3.12.6 - Melhorar a percepção do consumidor da qualidade dos produtos/serviços da empresa \\
\hline 3.12.7 - Garantir a realização de certificação de qualidade \\
\hline 3.12.8 - Garantir que a empresa não agride o meio circundante no exercício da sua actividade \\
3.12.9 - Demonstrar que com a prática de responsabilidade social têm o apoio governamental e / ou \\
europeu para financiamento de projectos \\
\hline 3.12.10 - Garantia do desenvolvimento sustentável da empresa e do meio circundante
\end{tabular}

Fonte: Elaboração própria.

Medição do impacto das dimensões da responsabilidade social na imagem das empresas

A responsabilidade social quando usada e comunicada estrategicamente impulsiona a imagem da empresa. É importante manter e desenvolver essa imagem organizacional. O impacto da responsabilidade social na imagem da empresa é objecto de estudo por diferentes autores em inúmeros periódicos e revistas entre os quais se destacam:

- Credidio (2002) Imagem é diferente de reputação.

- Mancera (2004) Maioria das pequenas empresas pratica ações de responsabilidade social.

- Bergamin (1999) Responsabilidade Social das Empresas Portuguesas: 25 Casos de Referência.

- Dias sobrinho (2005) responsabilidade social e imagem corporativa de uma instituição de ensino superior na percepção do corpo docente.

Estes autores, entre outros já revistos anteriormente, permitiram destacar na revisão bibliográfica dos seus artigos uma lista de indicadores que permitem aferir o grau de responsabilidade social e o seu impacto sobre a imagem organizacional. 
No quadro 6 estão representados os 12 indicadores que integram a escala de medida do impacto dos elementos da responsabilidade social para as empresas que constituem a amostra (ELEinf).

\section{Quadro no 6 \\ Escala de medida do impacto da responsabilidade social na imagem das empresas (ELEinf)}

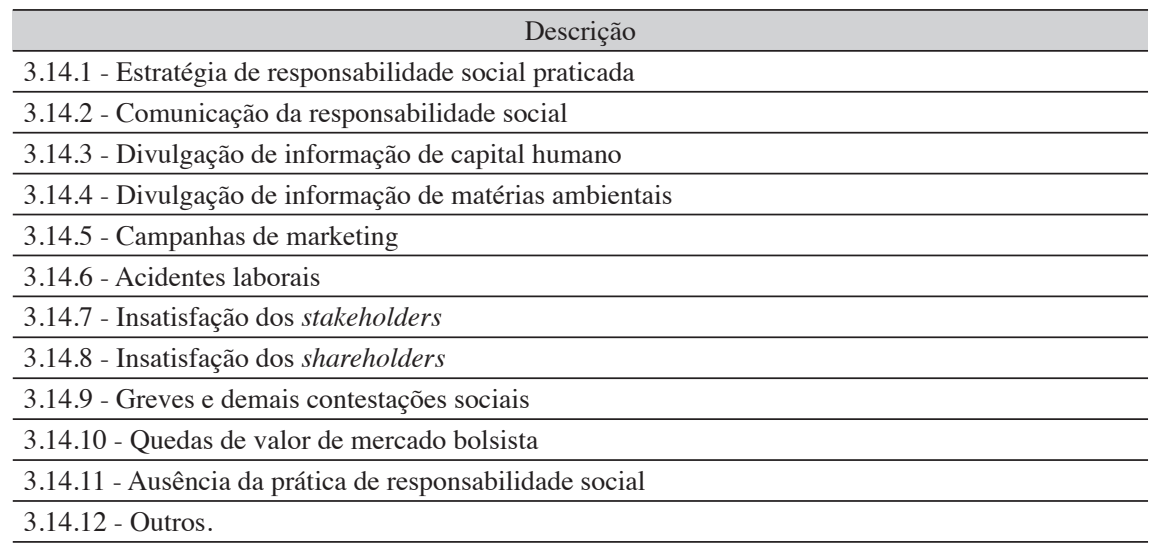

Fonte: Elaboração própria.

\section{Atitude da empresa face à responsabilidade social}

Para analisar a importância que as empresas dão à questão da responsabilidade social apresenta-se o gráfico 1 . Como se pode observar, quase $64 \%$ das empresas da amostra declaram ter uma atitude passiva face à responsabilidade social, ou seja, as questões da responsabilidade social não estão integradas na gestão das empresas, e mais de 34\% declaram ter uma atitude reactiva, isto é, consideram que a responsabilidade social impõe uma série de obrigações que há que cumprir para evitar males maiores. Cabe destacar que nenhuma das empresas declara que a sua atitude face à responsabilidade social é proactiva e 1,3\% das empresas definem a sua atitude face à responsabilidade social como excelente. 


\section{Gráfico 1}

\section{Atitude das empresas da amostra face à responsabilidade social}

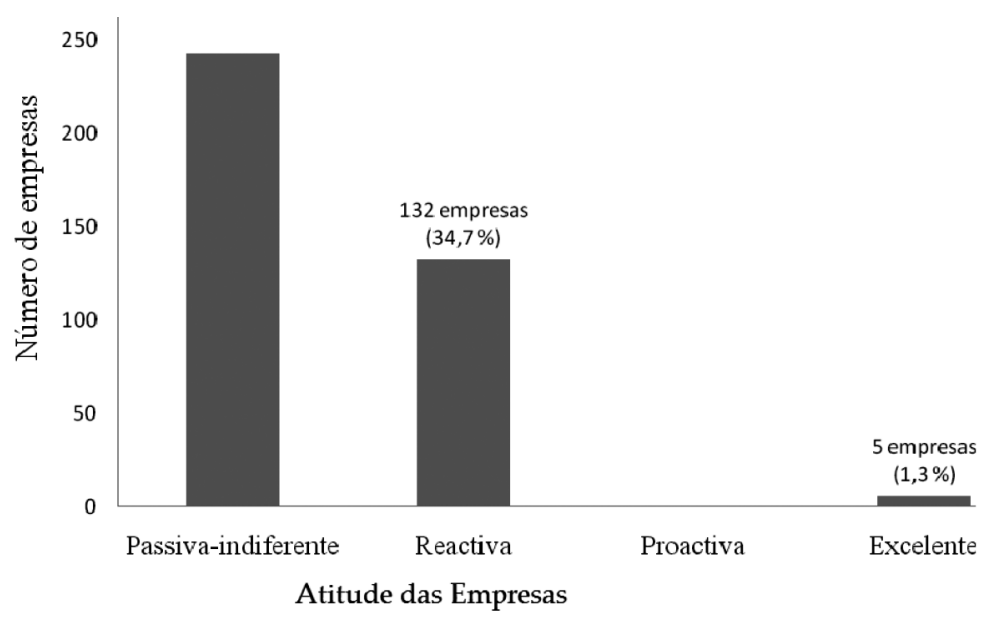

Ao analisar se a atitude da empresa face à responsabilidade social está relacionada com o seu tamanho, os resultados obtidos mostram que existe uma correlação muito baixa entre estas duas variáveis. Assim, não se pode afirmar que as empresas em estudo que têm maior dimensão apresentam uma atitude mais favorável relativamente à responsabilidade social.

Analisou-se também se a atitude das empresas variava em função da sua natureza pública ou privada. Comprovou-se que existe uma relação significativa entre a atitude das empresas e o facto de a sua natureza ser de carácter público (quadro 8).

\section{Quadro 8}

Correlação entre a atitude das empresas e a sua natureza (pública ou privada)

\begin{tabular}{l|c|c}
\hline \multicolumn{1}{c|}{ Chi - Quadrado de Pearson } & Valor & Nível de significância \\
\hline Natureza: Pública & 27.627 & $0.000^{\text {a }}$ \\
\hline Phi e V de Cramer & 0.270 & 0.000 \\
\hline Coeficiente de contigência & 0.260 & 0.000 \\
\hline Natureza: Privada & 8.387 & $0.031^{\text {a }}$ \\
\hline Phi e V de Cramer & 0.335 & 0.067 \\
\hline Coeficiente de contigência & 0.159 & 0.059 \\
\hline
\end{tabular}




\section{Validação das escalas de medida}

É interessante conhecer o grau de impacto económico das empresas na sociedade circundante, quais são as razões que explicam os critérios que influenciam a adopção da responsabilidade social por parte das empresas, os aspectos relevantes associados à função estratégica da comunicação da responsabilidade social para a actividade das empresas assim como o interesse por conhecer qual é a influência da responsabilidade social na imagem das empresas. Para este efeito inclui-se no quadro $\mathrm{n}^{\circ} 9$ um resumo descritivo da informação obtida com respeito à investigação realizada.

Como se pode comprovar a satisfação do impacto económico em média é maior relativamente à criação de emprego. A escassa distância surgem os objectivos ligados à criação de riqueza. Os aspectos relacionados com o impacto económico do desempenho da empresa no âmbito da responsabilidade social surgem em terceiro lugar e, por último a preocupação com a imagem da empresa. O critério que mais influencia a adopção da responsabilidade social por parte das empresas que compõem a amostra foi o crescimento económico. Muito próxima se situa a continuação da razão da aparição dos direitos humanos. Em terceiro lugar aparece a razão da necessidade de relato da responsabilidade social. Também se deve realçar que nos últimos lugares do ranking as razões para a adopção da responsabilidade social residem no aparecimento das instituições sociais e de apoio do estado nacional.

Os aspectos relevantes associados à função estratégica da comunicação da responsabilidade social para a actividade das empresas observa-se nos itens 2.3.3, 2.3.5 e 2.3.9 que ocupam um lugar de destaque nos objectivos estratégicos de comunicação destas empresas.

Por último, em termos da influência da responsabilidade social na imagem das empresas, o elemento que mais se destaca corresponde ao item 2.4.2 (comunicação da responsabilidade social) seguido por dois elementos correspondentes aos itens 2.4.1 e 2.4.5. nos últimos lugares figuram os itens 2.4.7, 2.4.8 e 2.4.12. 


\section{Quadro 9}

Satisfação com o impacto da empresa na sociedade (IMPeco), critérios para a adopção da responsabilidade social (APArse), relevância do impacto da comunicação da responsabilidade social (FUNcom) e elementos da RSE que influenciam a imagem da empresa (SOCima)

\begin{tabular}{|c|c|c|c|c|c|c|c|}
\hline Escala & Variável & 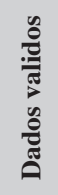 & 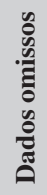 & & 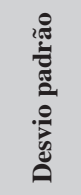 & 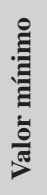 & 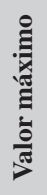 \\
\hline \multirow{4}{*}{ IMPeco } & 2.1.1. Criação de emprego & 380 & 0 & 3.71 & 0.563 & 2 & 5 \\
\hline & 2.1.2. Criação de riqueza & 380 & 0 & 3,46 & 0.564 & 2 & 5 \\
\hline & 2.1.3. Desempenho da empresa & 380 & 0 & 3,26 & 0.568 & 2 & 5 \\
\hline & 2.1.4. Imagem organizacional & 380 & 0 & 2.77 & 1.374 & 1 & 5 \\
\hline \multirow{11}{*}{ APArse } & 2.2.1. Crescimento económico & 380 & 0 & 4.74 & 0.438 & 4 & 5 \\
\hline & 2.2.2. Aparecimento dos direitos humanos & 380 & 0 & 4.43 & 0.496 & 4 & 5 \\
\hline & $\begin{array}{l}\text { 2.2.3. Emergência da certificação de } \\
\text { qualidade }\end{array}$ & 380 & 0 & 3.47 & 0.716 & 3 & 5 \\
\hline & $\begin{array}{l}\text { 2.2.4. Normalização de responsabilidade } \\
\text { social }\end{array}$ & 380 & 0 & 3.48 & 0.717 & 3 & 5 \\
\hline & \begin{tabular}{|l|}
$\begin{array}{l}\text { 2.2.5. Necessidade de relato da } \\
\text { responsabilidade social }\end{array}$ \\
\end{tabular} & 380 & 0 & 4.28 & 0.862 & 3 & 5 \\
\hline & 2.2.6. Exigência social & 380 & 0 & 4.05 & 0.913 & 2 & 5 \\
\hline & 2.2.7. Concepção de benefícios sociais & 380 & 0 & 3.18 & 0.627 & 2 & 4 \\
\hline & 2.2.8. Aparecimento de instituições sociais & 380 & 0 & 2.27 & 0.484 & 2 & 4 \\
\hline & 2.2.9. Apoio da igreja e da religião & 380 & 0 & 2.51 & 0.565 & 2 & 4 \\
\hline & 2.2.10. Apoio dos sindicatos e outras & 380 & 0 & 2.52 & 0.566 & 2 & 4 \\
\hline & 2.2.11. Apoio do estado nacional & 380 & 0 & 2,43 & 0.547 & 2 & 4 \\
\hline \multirow{10}{*}{ FUNcom } & 2.3.1. Aumento da visibilidade na imagem & 380 & 0 & 1.61 & 0.489 & 1 & 2 \\
\hline & 2.3.2. Aumento do valor da marca & 380 & 0 & 1.59 & 0.493 & 1 & 2 \\
\hline & $\begin{array}{l}\text { 2.3.3. Aumento do desempenho } \\
\text { organizacional }\end{array}$ & 380 & 0 & 1.86 & 0.348 & 1 & 2 \\
\hline & 2.3.4. Maior formação de lucros & 380 & 0 & 1.63 & 0.483 & 1 & 2 \\
\hline & 2.3.5. Associação prioritária dos objectivos & 380 & 0 & 1.95 & 0.214 & 1 & 2 \\
\hline & 2.3.6. Melhorar a percepção do consumidor & 380 & 0 & 1.1 & 0.295 & 1 & 2 \\
\hline & 2.3.7. Garantir a realização de certificação & 380 & 0 & 1.16 & 0.364 & 1 & 2 \\
\hline & 2.3.8. Garantir que a empresa não provoca & 380 & 0 & 1.15 & 0.356 & 1 & 2 \\
\hline & $\begin{array}{l}\text { 2.3.9. Demonstrar que com a prática da } \\
\text { RSE }\end{array}$ & 380 & 0 & 1.92 & 0.275 & 1 & 2 \\
\hline & $\begin{array}{l}\text { 2.3.10. Garantir o desenvolvimento } \\
\text { sustentável }\end{array}$ & 380 & 0 & 1.45 & 0.498 & 1 & 2 \\
\hline
\end{tabular}




\begin{tabular}{|c|c|c|c|c|c|c|c|}
\hline \multirow{12}{*}{ SOCima } & 2.4.1. Estratégia de responsabilidade social & 380 & 0 & 4.59 & 0.812 & 1 & 5 \\
\hline & $\begin{array}{l}\text { 2.4.2. Comunicação da responsabilidade } \\
\text { social }\end{array}$ & 380 & 0 & 4.58 & 0.775 & 2 & 5 \\
\hline & 2.4.3. Divulgação da informação de capital & 380 & 0 & 3.94 & 0.508 & 3 & 5 \\
\hline & 2.4.4. Divulgação de informação de matérias & 380 & 0 & 3.93 & 0.496 & 3 & 5 \\
\hline & 2.4.5. Campanhas de marketing & 380 & 0 & 4.86 & 0.495 & 2 & 5 \\
\hline & 2.4.6. Acidentes laborais & 380 & 0 & 2.35 & 1.13 & 1 & 5 \\
\hline & 2.4.7. Insatisfação dos stakeholders & 380 & 0 & 1.89 & 1.064 & 1 & 5 \\
\hline & 2.4.8. Insatisfação dos shareholders & 380 & 0 & 1.88 & 1.063 & 1 & 5 \\
\hline & 2.4.9. Contestações sociais & 380 & 0 & 3.03 & 0.311 & 2 & 5 \\
\hline & 2.4.10. Baixa no valor de mercado & 380 & 0 & 3.24 & 0.568 & 2 & 5 \\
\hline & 2.4.11. Ausência da prática & 380 & 0 & 3.04 & 0.292 & 2 & 5 \\
\hline & 2.4.12. Outros & 380 & 0 & 1.99 & 0.814 & 1 & 5 \\
\hline
\end{tabular}

Na continuação determinou-se a consistência da escala interna IMPeco a partir do Alfa de Cronbach obtendo-se um valor de 0.697 que se considera aceitável. Não obstante ao comprovar a fiabilidade da escala observa-se que eliminando o item 2.1.1 (criação de emprego) há uma melhoria no valor do Alfa de Cronbach e que a correlação deste elemento com a correlação total é corrigida somente em 32.3\%. Entretanto optou-se por eliminar inicialmente este item da escala pois a melhoria do Alfa é pequena e o objectivo de criar emprego está latente em qualquer empresa.

Há que indicar que embora depois de se verificar que a medida de adequação da amostra de Kaiser-Meyer-Olkin (KMO) apresenta um valor adequado (0.762) e que a prova de esfericidade de Bartlett é negativa, realizou-se uma análise factorial $^{3}$ de componentes principais cujos resultados se encontram no quadro 10. A matriz de componentes demonstra que existe somente um factor que explica $61.6 \%$ da variância.

\section{Quadro 10}

\section{Composição e fiabilidade da escala para a medição do impacto económico (IMPeco)}

\begin{tabular}{|c|c|c|c|}
\hline Variável & Componente 1 & Carga & Factor \\
\hline 1.1.1. Criação de emprego & 0.592 & 0.240 & \multirow{4}{*}{$\begin{array}{c}\text { Impacto económico } \\
\text { (FAC-IMPeco) } \\
\text { Alfa de Cronbach } \\
0.697\end{array}$} \\
\hline 1.1.2. Criação de riqueza & 0.944 & 0.383 & \\
\hline 2.1.3. Desempenho da empresa na RS & 0.740 & 0.300 & \\
\hline 2.1.4. Imagem organizacional & 0.821 & 0.333 & \\
\hline
\end{tabular}

\footnotetext{
${ }^{3}$ Foi feita esta análise porque as variáveis que formam os factores encontram-se na mesma escala de medida que o factor FUNcom e este foi formado independentemente dos restantes factores.
} 
Ao comprovar a fiabilidade da escala (quadro 11) observa-se que eliminando o item 3.3.1 relativo ao crescimento económico assim como o item 3.3.5 relativo à necessidade do relato da responsabilidade social melhora-se o valor do alfa de Cronbach, tanto mais que estes itens apresentam uma baixa correlação com os restantes elementos. Deste modo decidiu-se eliminar estes dois itens.

\section{Quadro 11}

Fiabilidade da escala APArse

\begin{tabular}{|l|c|c|c|c|}
\hline & $\begin{array}{c}\text { Média da escala } \\
\text { se se elimina o } \\
\text { elemento }\end{array}$ & $\begin{array}{c}\text { Variança } \\
\text { da escala se } \\
\text { se elimina o } \\
\text { elemento }\end{array}$ & $\begin{array}{c}\text { Correlação } \\
\text { elemento - total } \\
\text { corrigida }\end{array}$ & $\begin{array}{c}\text { Alfa de } \\
\text { Cronbach se } \\
\text { se elimina o } \\
\text { elemento }\end{array}$ \\
\hline 3.3 .1 - Crescimento económico & 32.616 & 13.841 & 0.134 & 0.757 \\
\hline 3.3 .2 - Aparecimento dos direitos humanos & 32.926 & 11.583 & 0.524 & 0.693 \\
\hline 3.3.3 - Emergência da certificação da qualidade & 33.892 & 10.350 & 0.593 & 0.672 \\
\hline 3.3.4 - Normalizaçao da responsabilidade social & 33.879 & 10.466 & 0.564 & 0.677 \\
\hline $\begin{array}{l}3.3 .5 \text { - Necessidade do relato da } \\
\text { responsabilidade social }\end{array}$ & 33.074 & 15.757 & 0.224 & 0.737 \\
\hline 3.3.6 - Exigência social & 33.308 & 9.707 & 0.537 & 0.679 \\
\hline 3.3.7 - Concessão de beneficios fiscais & 34.174 & 11.474 & 0.407 & 0.703 \\
\hline 3.3.8 - Aparecimento de instituições sociais & 35.090 & 11.569 & 0.545 & 0.691 \\
\hline 3.3.9 - Apoio da igreija e da religião & 34.853 & 10.733 & 0.688 & 0.667 \\
\hline $\begin{array}{l}3.3 .10 \text { - Apoio dos sindicatos e outras } \\
\text { instituições similares }\end{array}$ & 34.842 & 10.619 & 0.722 & 0.662 \\
\hline 3.3.11 - Apoio do estado nacional & 34.926 & 10.881 & 0.670 & 0.671 \\
\hline
\end{tabular}

Após comprovar-se que a Medida de adequação amostral KMO apresentava um valor adequado $(0,766)$ e que a prova de esfericidade de Bartlett era negativa, realizou-se uma análise factorial exploratória de componentes principais com rotação Varimax, cujos resultados se apresentam no quadro ${ }^{\circ} 12$, que mostram a existência de dois factores, que explicam $73,1 \%$ da variância. 


\section{Quadro 12}

Matriz de componentes rodadas da escala APArse

\begin{tabular}{l|c|c}
\hline \multirow{2}{*}{ Variável } & \multicolumn{2}{c}{ Componentes } \\
\cline { 2 - 3 } & $\mathbf{1}$ & $\mathbf{2}$ \\
\hline Aparecimento dos direitos humanos & 0.765 & 0.063 \\
\hline Emergência da certificação de qualidade & 0.089 & 0.943 \\
\hline Normalizaçao da responsabilidade social & 0.062 & 0.954 \\
\hline Exigência social & 0.756 & 0.251 \\
\hline Concessão de beneficios fiscais & 0.77 & -0.201 \\
\hline Aparecimento de instituições sociais & 0.365 & 0.63 \\
\hline Apoio da igreija e da religião & 0.817 & 0.323 \\
\hline Apoio dos sindicatos e outras instituições similares & 0.848 & 0.344 \\
\hline Apoio do estado nacional & 0.839 & 0.255 \\
\hline
\end{tabular}

No quadro 13 apresenta-se o constructo Adopção da Responsabilidade Social na sua versão definitiva. As cargas das variáveis sobre os factores representados neste quadro são o resultado de uma nova análise factorial confirmatória que não considera as variáveis antes excluídas. Os alfas mostrados por constructo no seu conjunto e os factores que o compõem são altamente satisfatórios, o que evidencia a sua fiabilidade.

\section{Quadro 13}

Escala para medição dos critérios na adopção da responsabilidade social. Composição e fiabilidade

\begin{tabular}{|c|c|c|}
\hline Variável & Carga & Factor \\
\hline 3.3.2 - Aparecimento dos direitos humanos & 0.216 & \multirow{6}{*}{$\begin{array}{c}\text { FAC-APArse 1 } \\
\text { (Acção social) } \\
\text { Alfa de Cronbach }=0.887\end{array}$} \\
\hline 3.3.6 - Exigência social & 0.187 & \\
\hline 3.3.7 - Concessão de beneficios fiscais & 0.254 & \\
\hline 3.3.9 - Apoio da igreija e da religião & 0.195 & \\
\hline 3.3.10 - Apoio dos sindicatos e outras instituições similares & 0.201 & \\
\hline 3.3.11 - Apoio do estado nacional & 0.211 & \\
\hline 3.3.3 - Emergência da certificação de qualidade & 0.413 & \multirow{3}{*}{$\begin{array}{c}\text { FAC-APArse 2 } \\
\text { (Regulamentação) } \\
\text { Alfa de Cronbach }=0.849\end{array}$} \\
\hline 3.3.4 - Normalizaçao da responsabilidade social & 0.422 & \\
\hline 3.3.8 - Aparecimento de instituições sociais & 0.234 & \\
\hline
\end{tabular}

Alfa de Cronbach total $=0.867$

A consistência dos aspectos relacionados com a função estratégica da comunicação da responsabilidade social para a actividade das empresas são apresentados 
no quadro 14. Como se pode observar, os itens 3.12.5, 3.12.9 e 3.12.3, ocupam um lugar destacado como objectivos estratégicos da comunicação destas empresas.

\section{Quadro 14}

\section{Relevância do impacto da comunicação da responsabilidade social}

\begin{tabular}{l|c|c|c|c|c|c}
\multicolumn{1}{c|}{ Variável } & $\begin{array}{c}\text { Dados } \\
\text { validos }\end{array}$ & $\begin{array}{c}\text { Dados } \\
\text { omissos }\end{array}$ & Media & $\begin{array}{c}\text { Desvio } \\
\text { padrão }\end{array}$ & $\begin{array}{c}\text { Valor } \\
\text { mínimo }\end{array}$ & $\begin{array}{c}\text { Valor } \\
\text { máximo }\end{array}$ \\
\hline 3.12.1 Aumento da visibilidade da imagem da empresa & 380 & 4 & 1.61 & 0.489 & 1 & 2 \\
\hline 3.12.2 Aumento do valor da marca & 380 & 4 & 1.59 & 0.493 & 1 & 2 \\
\hline 3.12.3 Aumento do desempenho organizacional & 380 & 4 & 1.86 & 0.348 & 1 & 2 \\
\hline 3.12.4 Maior formação de lucros & 380 & 4 & 1.63 & 0.483 & & 2 \\
\hline $\begin{array}{l}\text { 3.12.5 Associação prioritária dos objectivos } \\
\text { organizacionais }\end{array}$ & 380 & 4 & 1.95 & 0.214 & 1 & 2 \\
\hline $\begin{array}{l}\text { 3.12.6 Melhor percepção do consumidor da qualidade } \\
\text { dos produtos/serviços }\end{array}$ & 380 & 4 & 1.10 & 0.295 & 1 & 2 \\
\hline $\begin{array}{l}\text { 3.12.7 Garantir a realização da certificação de } \\
\text { qualidade }\end{array}$ & 380 & 4 & 1.16 & 0.364 & 1 & 2 \\
\hline $\begin{array}{l}\text { 3.12.8. Garantir que a empresa não agride o meio } \\
\text { ambiente }\end{array}$ & 380 & 4 & 1.16 & 0.356 & 1 & 2 \\
\hline 3.12.9. Apoio governamental através de práticas de RS & 380 & 4 & 1.92 & 0.275 & 1 & 2 \\
\hline 3.12.10 Garantia do desenvolvimento sustentável & 380 & 4 & 1.45 & 0.498 & 1 & 2 \\
\hline
\end{tabular}

Fonte: Elaboração própria.

No sentido de verificar se a dimensão das empresas tem alguma influência sobre o modo como estas entendem a função estratégica da comunicação da responsabilidade social, foi feita a prova de Kruskal-Wallis. Esta prova demonstra que a dimensão das empresas tem impacto relativamente aos itens 3.12.1, 3.12.2, 3.12.4 e 3.12.10.

Com o intuito de melhor observar estas diferenças foi realizada a prova de $\mathrm{U}$ de Mann-Whitney. Observa-se, por um lado, que as empresas de média dimensão dão mais importância que as empresas de pequena dimensão às questões relacionadas com o aumento da formação de lucros, por outro, que as empresas de grande dimensão valorizam mais que as pequenas empresas o aumento do valor da marca e a garantia do desenvolvimento sustentável e, ainda, as empresas de maior dimensão relativamente às empresas de média dimensão dão mais importância ao aumento da visibilidade da sua imagem.

No caso da atitude das empresas face à responsabilidade social, a prova de Kruskal-Wallis demonstra que existem diferenças significativas no grau de importância 
que as empresas concedem às distintas funções estratégicas da comunicação da responsabilidade social relativamente aos itens 3.12.1, 3.12.2, 3.12.4, 3.12.9 e 3.12.10. O resultado destas diferenças obtidas através da prova de U de Mann-Whitney permitem observar por um lado, que as empresas cuja atitude é reactiva face às passivas valorizam mais o aumento da visibilidade da imagem da empresa, o aumento do valor da marca e a garantia do desenvolvimento sustentável, por outro, que as empresas cuja atitude é excelente face às passivas atribuem mais valor ao apoio governamental e à garantia do desenvolvimento sustentável e, ainda, que as empresas cuja atitude é excelente face às reactivas dão maior importância às questões relacionadas com o aumento da visibilidade da imagem da empresa, o aumento do valor da marca, maior formação de lucros e ao apoio governamental.

Para finalizar a análise da função estratégica da comunicação da responsabilidade social nas empresas que constituem a amostra, determinou-se a consistência interna da escala dos critérios que orientam estas empresas nessa função estratégica (FUNcom) com base no cálculo do alfa de Cronbach, cujo valor de 0,721 é satisfatório. Ao comprovar a fiabilidade da escala observa-se que eliminando qualquer um dos itens 3.12.3, 3.12.5, 3.12.6, 3.12.7,3.12.8 e 3.12.9 o valor de alfa de Cronbach aumenta. Deste modo decidiu-se eliminar estes seis itens. Após se ter eliminado os itens mencionados, verificou-se que a Medida de adequação amostral KMO apresentava um valor adequado de 0,841 e que a prova de esfericidade de Bartlett era negativa, tendo-se realizado posteriormente uma análise factorial de componentes principais cujos resultados se apresentam no quadro 15. Como se pode observar, a matriz de componentes comprova a existência de um só factor que explica $83,9 \%$ da variância.

\section{Quadro 15}

\section{Análise factorial. Matriz de Componentes}

\begin{tabular}{l|c}
\hline \multicolumn{1}{c|}{ Variável } & Componente \\
\hline 3.12.1 Aumento da visibilidade da imagem da empresa & 0.941 \\
\hline 3.12.2 Aumento do valor da marca & 0.937 \\
\hline 3.12.4 Maior formação de lucros & 0.945 \\
\hline 3.12.10 Garantia do desenvolvimento sustentável & 0.835 \\
\hline \multicolumn{2}{c}{ Método de extracção: Análise de Componentes Principais } \\
\hline
\end{tabular}

Fonte: Elaboração própria

No quadro 16 encontra-se representado o constructo da função estratégica da comunicação da responsabilidade social na sua versão final. 


\section{Quadro 16 \\ Composição e fiabilidade da escala para a medição da função estratégica da comunicação}

\begin{tabular}{|c|c|c|}
\hline Variável & Carga & Factor \\
\hline 3.12.1 Aumento da visibilidade da imagem da empresa & 0.281 & \multirow{4}{*}{$\begin{array}{c}\text { Função estratégica da } \\
\text { comunicação } \\
\text { (FAC-FUNcom) } \\
\text { Alfa de Cronbach }=0.935\end{array}$} \\
\hline 3.12.2 Aumento do valor da marca & 0.279 & \\
\hline 3.12.4 Maior formação de lucros & 0.282 & \\
\hline 3.12.10 Garantia do desenvolvimento sustentável & 0.249 & \\
\hline
\end{tabular}

Fonte: Elaboração própria.

Para finalizar procurou-se perceber o interesse em conhecer qual a influência da responsabilidade social na imagem das empresas. O elemento que mais se destaca corresponde ao item 3.14.2 (Comunicação da responsabilidade social), seguido de perto por mais dois elementos correspondentes aos itens 3.14.1 e 3.14.5. Nos últimos lugares figuram os itens 3.14.7, 3.14.8 e 3.14.12. Feita a prova de Kruskal-Wallis os valores obtidos revelam que a dimensão das empresas tem influência em três dimensões correspondentes aos itens 3.14.2, 3.14.7 e 3.14.12. A análise detalhada destas diferenças revela que as empresas de grande dimensão dão mais importância às questões relacionadas com os três elementos (itens 3.14.2, 3.14.7 e 3.14.12) do que as empresas de pequena dimensão. A atitude das empresas face à responsabilidade social influencia a imagem destas, e manifesta-se diferentemente nas várias dimensões que influenciam a sua própria imagem, excepto nos casos correspondentes aos itens 3.14.9, 3.14.11 e 3.14.12.

Para finalizar a análise do impacto da responsabilidade social na imagem das empresas determinou-se a consistência interna da escala SOCima a partir do alfa de Cronbach, obtendo-se um valor de 0.710 , que se considera razoável. Não obstante, ao comprovar a fiabilidade da escala observa-se que eliminando qualquer um dos itens 3.14.1 ou 3.14.2 o valor do alfa de Cronbach melhora. Decidiu-se, deste modo, excluir estes dois itens, tanto mais que a correlação, quer de um, quer de outro, com a correlação total corrigida é inferior a 10\%. Após a eliminação dos dois itens mencionados, verificou-se que a Medida de adequação amostral KMO apresentava um valor adequado de 0.857 e que a prova de esfericidade de Bartlett era negativa, tendo-se realizado posteriormente uma análise factorial de componentes principais cujos resultados se apresentam no quadro 17 . Como se pode observar, a matriz de componentes comprova a existência de três factores que explicam $80.4 \%$ da variância. 
Quadro 17

Análise factorial. Matriz de Componentes

\begin{tabular}{l|c|c|c}
\hline & \multicolumn{3}{|c}{ Componentes } \\
\cline { 2 - 4 } & $\mathbf{1}$ & $\mathbf{2}$ & $\mathbf{3}$ \\
\hline 3.14.3 - Divulgação de informação de capital humano & 0.035 & 0.967 & 0.180 \\
\hline 3.14.4 - Divulgação de informação de matérias ambientais & 0.001 & 0.963 & 0.212 \\
\hline 3.14 .5 - Campanha de marketing & -0.337 & 0.670 & 0.211 \\
\hline 3.14.6 - Acidentes laborais & -0.819 & 0.045 & 0.046 \\
\hline 3.14 .7 - Insatisfação dos stakholders & -0.958 & -0.021 & 0.089 \\
\hline 3.14 .8 - Insatisfação dos shareholders & -0.958 & -0.021 & 0.089 \\
\hline 3.14 .9 - Greves e demais contestações sociais & 0.230 & 0.216 & -0.825 \\
\hline 3.14 .10 - Quedas de valor de mercado bolsista & 0.463 & -0.459 & -0.626 \\
\hline 3.14 .11 - Ausência da pratica de responsabilidade social & 0.370 & 0.188 & -0.713 \\
\hline 3.14 .12 - Outros & -0.790 & -0.020 & 0.233 \\
\hline
\end{tabular}

Método de extracção: Análise de componentes principais

Método de rotação: Normalização Varimax com Kaiser (a rotação convergiu em 5 iterações)

No quadro 18 apresenta-se o constructo impacto da responsabilidade social na imagem da empresa na sua versão definitiva.

\section{Quadro 18}

\section{Composição e fiabilidade da escala para a medição do impacto da responsabilidade social na imagem da empresa}

\begin{tabular}{|c|c|c|}
\hline & Carga & Factor \\
\hline 3.14.3 - Divulgação de informação de capital humano & 0.453 & \multirow{3}{*}{$\begin{array}{c}\text { FAC-SOCima } 1 \\
\text { (Divulgação) } \\
\text { Alfa de Cronbach }=0.784\end{array}$} \\
\hline 3.14.4 - Divulgação de informação de matérias ambientais & 0.444 & \\
\hline 3.14.5 - Campanha de marketing & 0.390 & \\
\hline 3.14.9 - Greves e demais contestações sociais & -0.394 & \multirow{3}{*}{$\begin{array}{c}\text { FAC-SOCima } 2 \\
\text { (Hostilização) } \\
\text { Alfa de Cronbach }=0.693\end{array}$} \\
\hline 3.14.10 - Quedas de valor de mercado bolsista & -0.349 & \\
\hline 3.14.11 -Ausência da pratica de responsabilidade social & -0.315 & \\
\hline 3.14.6 - Acidentes laborais & -0.252 & \multirow{4}{*}{$\begin{array}{c}\text { FAC-SOCima 3 } \\
\text { (Desregulamentação) } \\
\text { Alfa de Cronbach }=0.917\end{array}$} \\
\hline 3.14.7 - Insatisfação dos stakholders & -0.286 & \\
\hline 3.14.8 - Insatisfação dos shareholders & -0.287 & \\
\hline 3.14 .12 - Outros & -0.212 & \\
\hline \multicolumn{3}{|c|}{ Alfa de Cronbach total $=0.803$} \\
\hline
\end{tabular}

\section{Exposição das hipóteses a contrastar}

Uma vez realizada a revisão da literatura expõem-se uma série de proposições que se encontram resumidas no quadro 19. 


\section{Quadro 19}

\section{Resumo das proposições derivadas da revisão da literatura}

\begin{tabular}{c|l}
\hline Proposição 1 & $\begin{array}{l}\text { A adopção e prática da responsabilidade social influem positivamente nos } \\
\text { resultados económicos das empresas. }\end{array}$ \\
\hline Proposição 2 & $\begin{array}{l}\text { A proactividade da responsabilidade social influi positivamente na acção das } \\
\text { instituições privadas e estatais. }\end{array}$ \\
\hline Proposição 3 & $\begin{array}{l}\text { A proactividade da gestão da comunicação da responsabilidade social influi } \\
\text { positivamente nos resultados económico-financeiros das empresas. }\end{array}$ \\
\hline Proposição 4 & $\begin{array}{l}\text { A estratégia da responsabilidade social pode influenciar positivamente ou } \\
\text { negativamente o resultado operativo das empresas. }\end{array}$ \\
\hline
\end{tabular}

Fonte: Elaboração própria.

Com base na depuração e análise das propriedades psicométricas das escalas de medida do impacto económico das empresas, dos critérios que influenciam a adopção da responsabilidade social, da função estratégica da comunicação da responsabilidade social e do impacto da comunicação da responsabilidade social na imagem da empresa, identificaram-se uma série de dimensões em cada uma destas escalas, que se resumem no quadro 20.

\section{Quadro 20}

\section{Dimensões dos principais constructos da investigação empírica}

\begin{tabular}{c|c|c}
\hline CONSTRUCTO & DIMENSÕES & DESCRIÇÃO \\
\hline Impacto Económico & FAC-IMPeco & Criação de valor para a sociedade \\
\hline $\begin{array}{c}\text { Adopção da } \\
\text { Responsabilidade Social }\end{array}$ & FAC-APArse 1 & Acção social \\
\cline { 2 - 3 } & FAC-APArse 2 & Regulamentação \\
\hline Imagem & FAC-FUNcom & Desenvolvimento e sustentabilidade \\
\hline \multirow{2}{*}{\begin{tabular}{c} 
Comunicação Resp. Social como estratégia \\
\cline { 2 - 3 }
\end{tabular}} & FAC-SOCima 1 & Divulgação \\
\cline { 2 - 3 } & FAC-SOCima 2 & Hostilização \\
\cline { 2 - 3 } & FAC-SOCima 3 & Desregulamentação \\
\hline
\end{tabular}

Consequentemente, as proposições iniciais desdobram-se em novas hipóteses que têm em conta estas dimensões. No quadro 21 enunciam-se as novas hipóteses agrupadas segundo as proposições de partida. 


\section{Quadro 21}

\section{Hipóteses derivadas a partir das proposições de partida}

\begin{tabular}{|c|c|}
\hline Hipótese & Descrição \\
\hline 1.1 & $\begin{array}{l}\text { A acção social influi positivamente nos resultados económicos das } \\
\text { empresas. }\end{array}$ \\
\hline 1.2 & $\begin{array}{l}\text { A acção de regulamentação influi positivamente nos resultados } \\
\text { económicos das empresas. }\end{array}$ \\
\hline 2.1 & $\begin{array}{l}\text { A proactividade da responsabilidade social influi positivamente na } \\
\text { acção das instituições privadas. }\end{array}$ \\
\hline 2.2 & $\begin{array}{l}\text { A proactividade da responsabilidade social influi positivamente na } \\
\text { acção das instituições públicas. }\end{array}$ \\
\hline 3.1 & $\begin{array}{l}\text { A proactividade da gestão da comunicação da responsabilidade } \\
\text { social influi positivamente nos resultados económico-financeiros das } \\
\text { empresas. }\end{array}$ \\
\hline 4.1 & $\begin{array}{l}\text { A estratégia da responsabilidade social pode influenciar positivamente } \\
\text { o resultado operativo das empresas. }\end{array}$ \\
\hline 4.2 & $\begin{array}{l}\text { A estratégia da responsabilidade social pode influenciar negativamente } \\
\text { o resultado operativo das empresas. }\end{array}$ \\
\hline
\end{tabular}

Fonte: Elaboração própria.

\section{Comparação e contraste de hipóteses e discussão dos resultados obtidos}

Para contrastar as sete hipóteses do quadro 21 realizou-se uma série de regressões múltiplas representadas no quadro 22, considerando em cada modelo as variáveis dependentes e independentes em função da hipótese a contrastar. As variáveis D1 e D2, são variáveis dummies de controlo, tamanho da empresa e atitude da empresa face à responsabilidade social, respectivamente. A constante $\mathrm{C}$ mede o efeito autónomo e $\varepsilon$ representa o erro de estimação.

No teste de hipóteses e na análise da variância, considerou-se os seguintes critérios: normalidade, homocedasticidade, independência dos erros e linearidade. A normalidade exige que os valores de Y sejam normalmente distribuídos em relação a X. A homocedasticidade presume que as variações na linha de regressão sejam constantes para todos os valores de X. A homocedasticidade é fundamental para a determinação dos coeficientes de regressão. A independência dos erros requer que o erro seja independente para cada valor de X. É fundamental quando se analisam dados recolhidos ao longo de um determinado período de tempo. A linearidade pressupõe que a relação entre as variáveis deve ser linear. 
Quadro 22

Modelos de regressão linear para contraste de hipóteses

\begin{tabular}{c|c|l}
\hline Hipótese & Modelo & \multicolumn{1}{c}{ Equação } \\
\hline & 1 & $($ FAC-IMPeco $)=\mathrm{C}+\mathrm{D} 1+\mathrm{D} 2+\varepsilon$ \\
\hline \multirow{2}{*}{1.1} & 1.1 & $($ FAC-IMPeco $)=\mathrm{C}+\mathrm{D} 1+\mathrm{D} 2+($ FAC-APArse 1$)+\varepsilon$ \\
\hline \multirow{2}{*}{1.2} & 1.2 & $($ FAC-IMPeco $)=\mathrm{C}+\mathrm{D} 1+\mathrm{D} 2+($ FAC-APArse 2$)+\varepsilon$ \\
\cline { 2 - 3 } & $2 \mathrm{a}$ & $($ FAC-APArse 1$)=\mathrm{C}+\mathrm{D} 1+\mathrm{D} 2+\varepsilon$ \\
\cline { 2 - 3 } & $2 \mathrm{~b}$ & $($ FAC-APArse 2$)=\mathrm{C}+\mathrm{D} 1+\mathrm{D} 2+\varepsilon$ \\
\hline 2.1 & 2.1 & $($ FAC-APArse 1$)=\mathrm{C}+\mathrm{D} 1+\mathrm{D} 2+($ FAC-FUNcom $)+$ FAC-SOCima 1$)+\varepsilon$ \\
\hline 2.2 & 2.2 & $($ FAC-APArse 2$)=\mathrm{C}+\mathrm{D} 1+\mathrm{D} 2+($ FAC-FUNcom $)+$ FAC-SOCima 1$)+\varepsilon$ \\
\hline 3.1 & 3.1 & $($ FAC-IMPeco $)=\mathrm{C}+\mathrm{D} 1+\mathrm{D} 2+($ FAC-FUNcom $)+\varepsilon$ \\
\hline 4.1 & 4.1 & $($ FAC-IMPeco $)=\mathrm{C}+\mathrm{D} 1+\mathrm{D} 2+($ FAC-SOCima 1$)+\varepsilon$ \\
\hline 4.2 & 4.2 & (FAC-IMPeco $)=\mathrm{C}+\mathrm{D} 1+\mathrm{D} 2+($ FAC-SOCima 2$)+($ FAC-SOCima 3$)+\varepsilon$ \\
\hline
\end{tabular}

Fonte: Elaboração própria.

O uso de variáveis de controlo D1 e D2 tem como propósito medir, por um lado, os efeitos das economias de escala e, por outro, os efeitos das diferentes forças competitivas prevalecentes no conjunto das empresas que constituem a amostra. Para contrastar as primeiras hipóteses (1.1. e 1.2.), propõem-se três modelos explicativos. No primeiro modelo (modelo 1) considerou-se unicamente o papel explicativo das variáveis de controlo; no segundo (modelo 1.1.1) aumentou-se as variáveis de controlo na dimensão de acção social e no terceiro modelo (modelo 1.2.) aumentou-se as variáveis de controlo na dimensão regulamentação.

Seguindo este esquema para cotejar o contraste das hipóteses 1.1. e 1.2. levaram-se a efeito três regressões tendo como variável independente o factor FAC-IMPeco, cujos resultados são apresentados no quadro 23 - efeito das dimensões da adopção da responsabilidade social. Para cada variável explicativa aparece descrito um coeficiente não estandardizado com um nível de significância e entre parênteses o valor da estatística de $t_{\text {student }}$ que estabelece o nível de confiança do coeficiente em causa.

Em cada modelo especifica-se também o valor do desvio padrão correspondente ao erro total, o coeficiente de determinação corrigido e o nível total de confiança através do $\mathrm{F}_{\text {estatístico }}$. $\mathrm{O}$ primeiro modelo explicativo no qual se incluem unicamente variáveis de controlo como variáveis explicativas, reflecte que tanto o tamanho da empresa como a sua atitude perante a responsabilidade social constituem variáveis relevantes para explicar o efeito do impacto económico. Os coeficientes de ambas 
as variáveis são positivos e significativos com um nível de confiança de 95\% e de $99 \%$ respectivamente.

Como se pode observar no modelo 1.1., a dimensão da acção social representada pela variável FAC-APArse 1 tem um factor positivo e significativo com um nível de significação de $99 \%$ e no modelo 1.2. a dimensão da regulamentação representada pela variável FAC-APArse 2 tem um efeito diminuído e não significativo estatisticamente.

É importante destacar que os efeitos das variáveis de controlo se manifestam significativos. Isto provavelmente deve-se ao facto das dimensões da acção social e da regulamentação estarem pouco relacionadas com as variáveis de controlo. Estes dados confirmam o que na revisão dos ensaios críticos sobre o tema se conseguiu concluir: a responsabilidade social está relacionada com o crescimento económico e também com outros aspectos mas este é o primordial. Sugere-se que em futuras investigações se possam incluir mais variáveis explicativas e verificar se os resultados obtidos contrastam com os actuais.

\section{Quadro 23}

Efeito das dimensões da adopção da responsabilidade social

\begin{tabular}{c|l|l|l|l|l|l|c|c}
\hline Modelo & \multicolumn{1}{|c|}{$\begin{array}{c}\text { C } \\
\text { Constante }\end{array}$} & $\begin{array}{c}\text { D1 } \\
\text { Dimensão }\end{array}$ & $\begin{array}{c}\text { D2 } \\
\text { Atitude }\end{array}$ & $\begin{array}{c}\text { FAC- } \\
\text { APArse 1 }\end{array}$ & $\begin{array}{c}\text { FAC- } \\
\text { APArse 2 }\end{array}$ & $\sigma_{\varepsilon}$ & $\mathbf{R}_{\text {corrigido }}$ & $\mathbf{F}_{\text {estatístico }}$ \\
\hline \multirow{2}{*}{1} & $\begin{array}{l}1.230^{* * * *} \\
(8.609)\end{array}$ & $\begin{array}{l}0.124^{* * *} \\
(2.461)\end{array}$ & $\begin{array}{l}1.023^{* * * *} \\
(13.814)\end{array}$ & & & 0.803 & 0.356 & 105.704 \\
\hline 1.1 & $\begin{array}{l}0.844^{* * * *} \\
(5.499)\end{array}$ & $\begin{array}{l}0.132^{* * * *} \\
(2.739)\end{array}$ & $\begin{array}{l}0.754^{* * * *} \\
(8.800)\end{array}$ & $\begin{array}{l}0.269^{* * * *} \\
(5.620)\end{array}$ & & 0.772 & 0.404 & 86.714 \\
\hline 1.2 & $1.272^{* * * *}$ \\
& $(8.552)$ & $\begin{array}{l}0.120^{* * *} \\
(2.379)\end{array}$ & $\begin{array}{l}1.049^{* * * *} \\
(13.377)\end{array}$ & & $\begin{array}{l}0.045^{*} \\
(1.023)\end{array}$ & 0.803 & 0.356 & 70.827 \\
\hline
\end{tabular}

**** Coeficiente estatisticamente significativo ao nível de $1 \%$

*** Coeficiente estatisticamente significativo ao nível de 5\%

** Coeficiente estatisticamente significativo ao nível de $10 \%$

* Coeficiente não estatisticamente significativo

(Entre parêntesis $t_{\text {student }}$ )

Os quatro modelos propostos para contrastar as hipóteses 2.1. e 2.2. (quadro 24) confirmam que a proactividade da responsabilidade social influi positivamente na acção das empresas tanto para as privadas como para as públicas. Todos os coeficientes das dimensões de desenvolvimento/sustentabilidade e divulgação são positivos e significativos com um nível de significância igual ou superior a 95\%. 
Note-se que o coeficiente da variável de controlo que mede o tamanho da empresa resulta não significativo em todos os modelos, indicando que a dimensão das empresas não influi positivamente na intensidade e na sua forma de actuar.

Em conformidade com o referido na revisão dos ensaios críticos sobre o tema verifica-se que a responsabilidade social é um aspecto positivo para as empresas que a colocam em prática. Independentemente do tamanho das empresas, o facto que realmente importa é a prática da responsabilidade social que influencia a sua maneira de actuação e competição no mercado.

\section{Quadro 24}

Efeito das dimensões da proactividade da responsabilidade social

\begin{tabular}{c|l|l|l|l|l|l|l|l}
\hline Modelo & \multicolumn{1}{|c|}{$\begin{array}{c}\text { C } \\
\text { Constante }\end{array}$} & \multicolumn{1}{|c|}{$\begin{array}{c}\text { D1 } \\
\text { Dimensão }\end{array}$} & $\begin{array}{c}\text { D2 } \\
\text { Atitude }\end{array}$ & $\begin{array}{c}\text { FAC- } \\
\text { FUNcom }\end{array}$ & $\begin{array}{c}\text { FAC- } \\
\text { SOCima 1 }\end{array}$ & $\sigma_{\varepsilon}$ & $\mathbf{R}_{\text {corrigido }}^{2}$ & F $_{\text {estatístico }}$ \\
\hline $2 \mathrm{a}$ & $\begin{array}{l}1.434^{* * * *} \\
(9.691)\end{array}$ & $\begin{array}{l}-0.035^{*} \\
(-0.625)\end{array}$ & $\begin{array}{l}0.998^{* * * *} \\
(13.018)\end{array}$ & & & 0.832 & 0.309 & 85.574 \\
\hline $2 \mathrm{~b}$ & $\begin{array}{l}0.952^{* * * *} \\
(5.656)\end{array}$ & $\begin{array}{l}-0.085^{*} \\
(-1.438)\end{array}$ & $\begin{array}{l}0.593^{* * * *} \\
(6.797)\end{array}$ & & & 0.947 & 0.305 & 23.200 \\
\hline 2.1 & $\begin{array}{l}0.507^{* * * * *} \\
(2.772)\end{array}$ & $\begin{array}{l}-0.038^{*} \\
(-0.760)\end{array}$ & $\begin{array}{l}0.328^{* * * *} \\
(2.929)\end{array}$ & $\begin{array}{l}0.474^{* * * *} \\
(7.582)\end{array}$ & $\begin{array}{l}0.103^{* * *} \\
(2.480)\end{array}$ & 0.776 & 0.399 & 63.158 \\
\hline 2.2 & $\begin{array}{l}0.289^{* * *} \\
(1.660)\end{array}$ & $\begin{array}{l}0.003^{*} \\
(0.074)\end{array}$ & $\begin{array}{l}0.200^{* *} \\
(1.871)\end{array}$ & $\begin{array}{l}0.174^{* * * *} \\
(2.927)\end{array}$ & $\begin{array}{l}0.614^{* * * *} \\
(15.494)\end{array}$ & 0.740 & 0.457 & 79.824 \\
\hline
\end{tabular}

**** Coeficiente estatisticamente significativo ao nível de $1 \%$

*** Coeficiente estatisticamente significativo ao nível de 5\%

** Coeficiente estatisticamente significativo ao nível de $10 \%$

* Coeficiente não estatisticamente significativo

(Entre parêntesis $t_{\text {student }}$ )

No caso das hipóteses 3.1. e 4.1. todas as dimensões da proactividade têm uma influência significativa e positiva no impacto económico (quadro 25). De referir que por impossibilidade da determinação de variáveis que medissem especificamente os resultados económicos e financeiros e também operativos das empresas, optou-se por num dos modelos utilizar a dimensão do impacto económico FAC-IMPeco como proxy das primeiras. A revisão de literatura sobre o tema confirma que as empresas que são proactivas no emprego e nas práticas socialmente responsáveis são mais atractivas aos olhos dos consumidores e conseguem sustentar-se mais e melhor no mercado de actuação e com isso expandir a sua actividade. 
No questionário não foi considerada nenhuma questão que implicasse a medição dos resultados líquidos, de resultados operacionais, de volume de negócios, de valor aumentado ou de outras variáveis sobre quantificações dos resultados económicos, na medida em que por falta de respostas e por poder-se utilizar variáveis proxys resolveu-se eliminar estas questões que poderão dar futuros estudos e formar parte para elaboração de novos resultados e de outras conclusões.

\section{Quadro 25}

Efeito das dimensões da proactividade da comunicação da responsabilidade social

\begin{tabular}{c|l|l|l|l|l|l|l|l}
\hline Modelo & \multicolumn{1}{|c|}{$\begin{array}{c}\text { C } \\
\text { Constante }\end{array}$} & $\begin{array}{c}\text { D1 } \\
\text { Dimensão }\end{array}$ & $\begin{array}{c}\text { D2 } \\
\text { Atitude }\end{array}$ & FAC-FUNcom & $\begin{array}{c}\text { FAC- } \\
\text { SOCima 1 }\end{array}$ & $\sigma_{\varepsilon}$ & $\mathbf{R}_{\text {corrigido }}$ & $\mathbf{F}_{\text {estatístico }}$ \\
\hline \multirow{2}{*}{3.1} & $0.423^{* * *}$ & $\begin{array}{l}0.103^{* * *} \\
(2.205)\end{array}$ & $\begin{array}{l}0.411^{* * * *} \\
(3.931)\end{array}$ & $\begin{array}{l}0.467^{* * * *} \\
(7.902)\end{array}$ & & 0.740 & 0.455 & 105.458 \\
\hline \multirow{2}{*}{4.1} & $1.319^{* * * *}$ & $0.102^{* * *}$ & $\begin{array}{l}1.062^{* * * *} \\
(14.326)\end{array}$ & & $\begin{array}{l}0.134^{* * * *} \\
(3.323)\end{array}$ & 0.793 & 0.372 & 75.687 \\
\hline
\end{tabular}

\footnotetext{
**** Coeficiente estatisticamente significativo ao nível de $1 \%$

*** Coeficiente estatisticamente significativo ao nível de 5\%

** Coeficiente estatisticamente significativo ao nível de $10 \%$

* Coeficiente não estatisticamente significativo
}

(Entre parêntesis $t_{\text {student }}$ )

Por último a hipótese 4.2. não se confirma (quadro 26). Os coeficientes de ambas as variáveis correspondentes às dimensões FAC-SOCima 2 e FAC-SOCima 3 têm um valor negativo mas tanto num caso como noutro não são significativas, ou seja, não têm influência significativa no impacto económico das empresas. Também aqui foi utilizada a dimensão impacto económico como proxy da dimensão resultado operativo das empresas.

A revisão de literatura sobre o tema permitiu inferir que a estratégia de responsabilidade social poderia potenciar os resultados e a actuação empresarial de uma empresa. Em concordância se comprova que neste estudo não existe influência significativa de FAC-SOCima 2 e FAC-SOCima 3 no resultado económico das empresas (o que pode ser bom desde a óptica individual de cada empresa, mas pode significar indiferença e pouca discriminação entre as empresas, ou seja, o mercado não penaliza as empresas que se portam mal). A dita revisão ilustrou a existência e continuidade de muitos negócios sem responsabilidade social mostrando que o mercado não apresenta mecanismos correctores para a falta ou inexistência de responsabilidade social ou do facto de esta não ser totalmente respeitada. 
Quadro 26

Efeito das dimensões da estratégia da responsabilidade social

\begin{tabular}{c|l|l|c|c|c|c|c|c}
\hline Modelo & $\begin{array}{c}\text { C } \\
\text { Constante }\end{array}$ & \multicolumn{1}{|c|}{$\begin{array}{c}\text { D1 } \\
\text { Dimensão }\end{array}$} & $\begin{array}{c}\text { D2 } \\
\text { Atitude }\end{array}$ & $\begin{array}{c}\text { FAC- } \\
\text { SOCima 2 }\end{array}$ & $\begin{array}{c}\text { FAC- } \\
\text { SOCima 3 }\end{array}$ & \multicolumn{1}{|c|}{$\sigma_{\varepsilon}$} & $\mathbf{R}_{\text {corrigido }}^{2}$ & $\mathbf{F}_{\text {estatistico }}$ \\
\hline \multirow{2}{*}{4.2} & $1.242^{* * * *}$ & $\begin{array}{l}0.125^{* * *} \\
(2.484)\end{array}$ & $\begin{array}{l}1.035^{* * * *} \\
(13.574)\end{array}$ & $\begin{array}{l}-0.032^{*} \\
(-0.769)\end{array}$ & $\begin{array}{l}-0.002^{*} \\
(-0.059)\end{array}$ & 0.804 & 0.353 & 52.804 \\
\hline
\end{tabular}

**** Coeficiente estatisticamente significativo ao nível de $1 \%$

*** Coeficiente estatisticamente significativo ao nível de 5\%

** Coeficiente estatisticamente significativo ao nível de $10 \%$

* Coeficiente não estatisticamente significativo

(Entre parêntesis $t_{\text {student }}$ )

\section{Conclusões e limitações do estudo}

Pode-se concluir que a responsabilidade social é uma vantagem competitiva nos negócios principalmente nas áreas que respeitam à comunidade circundante. Impulsionam a imagem da empresa e também auxiliam à sustentabilidade financeira e não financeira ao longo do tempo. Garante que as empresas observem não só o ambiente como os aspectos sociais que digam respeitam aos trabalhadores, fornecedores, Estado e todos os outros stakeholders que actuam com a empresa. A responsabilidade social é uma prática que ao ser protagonizada por uma empresa tenderá também a ser imitada por outras e por alguns dos seus colaboradores e intervenientes.

Em Portugal a actuação socialmente responsável é insuficiente diante da que é realizada na Europa ou na América do Sul. As empresas portuguesas, particularmente as que foram objecto de estudo (empresas da Maia) não respeitam com a devida observação os impactos que poderiam obter no uso da responsabilidade social. Os negócios estão a perder oportunidades e as empresas não estão a garantir um futuro sustentável para todos. Não são somente as empresas que estão a perder mas todos nós portugueses que intervimos com tais empresas. Com respeito ao estudo empírico podemos inferir, com base no questionário realizado, que as micro e pequenas empresas dominam o universo de negócios e, que nessas empresas os trabalhadores estão satisfeitos com a criação de emprego, mas não tanto com a criação de riqueza e desempenho da empresa quer no âmbito da responsabilidade social quer no âmbito da imagem organizacional. Embora os trabalhadores juntamente com os clientes, fornecedores, accionistas e detentores de capital sejam os stakeholders mais importantes, aos quais esta pretende agradar, nem para estes executa ou co- 
munica, com expressão significativa, acções de responsabilidade social. Quando tal facto ocorre os meios de comunicação ou os canais privilegiados pelas empresas são: internet e o marketing tradicional. Assim se percebe que a função estratégica da comunicação da responsabilidade social é influenciar os consumidores, fidelizar clientes, manter a sustentabilidade no mercado e garantir a realização da certificação de qualidade. A informação contabilística não é expressivamente utilizada pelas empresas maiatas, particularmente o balanço social. A maioria da informação contabilística que é divulgada é qualitativa e é feita como complemento à informação financeira. A maioria das empresas apresenta dificuldades no âmbito do relato social: classificação, divulgação, mensuração, identificação, reconhecimento e conceituação. Devido aos problemas de relato elencados as empresas têm tido esta resposta para justificar a ausência de redacção e divulgação de informação sobre responsabilidade social. O impacto da responsabilidade social sobre os resultados das empresas da Maia não é significativo, facto que condiciona a sua expressividade e crescimento. Talvez pelo facto do mercado ser indiferente às práticas sociais as empresas que não praticam a responsabilidade social não se situam em patamares abaixo das que executam práticas sociais. Na Maia não há evidência de que as empresas que praticam a responsabilidade social tenham melhores resultados ou a sua performance seja superior às demais empresas. A falta de relação entre desempenho económico e resultados nas empresas objecto de estudo leva a inferir que estas empresas deveriam modificar as suas estratégias ou até a forma de divulgação da informação social uma vez que a pouca expressividade pode provocar o abandono de algumas práticas de responsabilidade social. A condicionar ainda mais este facto anote-se que o estudo empírico limitou-se a um questionário, realizado no perímetro nacional concretamente nas empresas da Maia. O estudo manifesta uma vertente essencialmente económico-financeira traçando uma abordagem social sobre os aspectos que merecem essa atenção. Estas limitações deverão ser eliminadas em futuros estudos para isso os mesmos poderão contemplar outras regiões e contrastar com os resultados agora obtidos ou, simplesmente, alargar o espectro de análise a outro tipo de informação que não apenas a financeira.

\section{Referências}

Ackerman, R. (1973). How companies respond to social demands. Harvard Business Review 51 (4): 34-57. 
Asociación Española de Contabilidad y Administración (2004). Marco Conceptual de la Responsabilidad Social Corporativa. Documento $\mathrm{N}^{\mathrm{o}} 1$, série RSC, $1^{\mathrm{a}}$. ed., Espanha. Disponível em: http://www.aeca.es

Amazeen, M. (2011). Gap (RED): Social Responsibility Campaign or Window Dressing? Journal of Business Ethics 99: 167-182.

Arlow, P. \& M. Gannon (1982). Social Responsiveness, Corporate Structure, and Economic Performance. The Academy of Management Review 7 (2): 235-241.

Bansal, S. \& L. Sharma (2006). New challenges of accounting and auditing in environment in India. In XI Congresso Internacional de Contabilidade e Auditoria, Coimbra, Portugal, 16-18 novembro 2006: 1-16.

Baxi, C. V. \& R. S. Ray (2009). Corporate Social \& Environmental Disclosures \& Reporting. The Indian Journal of Industrial Relations 44 (3): 355-375.

Bergamin Jr., S. (1999). Contabilidade e riscos ambientais. Revista do BNDES Banco Nacional de desenvolvimento Económico e Social: 1-23.

Brookson, S. (2003). Como entender a Contabilidade. Trad. Anna Quirino. São Paulo: Publifolha.

Burke, L. \& J. M. Logsdon, (1996). How corporate Social Responsibility pays off. Long Range Planning 29 (4): 495-502.

Callado, A. L. C. \& J. E. Fensterseifer (2011). Corporate Sustainability Measure From An Integrated Perspective: The Corporate Sustainability Grid (CSG). Special Issue IJBIT 3 (3): 44-55.

Campos, F., M. de Moreno \& C. F. Lemme (2007). Exame Da Metodologia Dos Índices Internacionais Do Mercado Acionário E Da Experiência Brasileira Na Área Do Investimento Socialmente Responsável. In IX ENGEMA Encontro Nacional Sobre Gestão Empresarial E Meio Ambiente, Curitiba, Brasil, 19-21 de novembro de 2007.

Carroll, Archie B. (1979). A three-dimensional conceptual model of corporate social performance. Academy of Management Review 4: 497-505. 
\& A. K. Buchholtz (1999). Business \& Society: Ethics and Stakeholder Management. Cincinnati: South-Western College Publishing.

Carvalho, J. B. C. \& S. M. S. Monteiro (2002). A Contabilização e Relato das Matérias Ambientais: Recentes Desenvolvimentos. Revista de Gestão e Economia 5: 65-83.

(2004). O Contributo da Contabilidade para a gestão ambiental das empresas certificadas pela ISO 14001. Jornal do Técnico de Contas e da Empresa 450: 116-123 et 451: 44-150.

Clarke, J. \& M. Gibson-Sweet (1999). The use of corporate social disclosure in the management of reputation and legitimacy: a cross sectoral analysis of UK Top 100 Companies. Business Ethics: A European Review 8 (1): 5-13.

Cortez, M. A. \& N. T. Penacerrada (2010). Is it beneficial to incur environmental cost? A case study of toyota motors corporation, Japan. Journal of International Business Research 1: 1-24.

Cowper-Smith, A. \& D. de Grosbois (2011). The adoption of corporate social responsibility practices in the airline Industry. Journal of Sustainable Tourism 19 (1): 59-77.

Credidio, F. A. (2002). Empresas e marketing cultural. Revista Marketing Cultural 72: 29-30.

Daft, R. L. (1999). Administração. 4a. ed. Rio de Janeiro: Prentice Hall do Brasil.

Dalton, R. \& R. Cosier (1982). The four faces of social responsibility. Business Horizons 1: 19-27.

Damak-Ayadi, S. (2009). Contribution on the analysis of the environmental disclosure: a comparative study of American and European multinationals. Social Responsibility Journal 5 (1): 83-93.

Dhaliwal, D. S., O. Z. Li, A. Tsang \& Y. G. Yang (2011). Voluntary Nonfinancial Disclosure and the Cost of Equity Capital: The Initiation of Corporate Social Responsibility Reporting. The accounting review 86 (1): 59-100. 
, S. Radhakrishnan, A. Tsang \& Y. G. Yang (2012). Nonfinancial Disclosure and Analyst Forecast Accuracy: International Evidence on Corporate Social Responsibility Disclosure. The Accounting Review 87 (3): 723-759.

Días Sobrinho, J. (2005). Educação superior, globalização e democratização: qual universidade? Revista Brasileira de Educação 10 (28): 164-173.

Ehrgott, M., F. Reimann, L. Kaufmann \& C. R. Carter. (2011). Social Sustainability in Selecting Emerging Economy Suppliers. Journal of Business Ethics 98 (1): 99-119.

Faria, M. J. S. (2012). Perspectivas de análise da informação financeira no relato de determinados elementos intangíveis. (Tese de doutoramento não publicada). Universidade de Santiago de Compostela, Departamento de Economia Financeira e Contabilidade, Espanha.

Farias, L. A. (2004). A Literatura de Relações Públicas: produção, consumo e perspectivas. São Paulo: Summus.

Farneti, F. \& J. Guthrie, J. (2007). Sustainability reporting by Australian public sector organisations: Why they report? 6th Australasian Conference on Social and Environmental Accounting Research (CSEAR), Sydney (The University of Sydney), 2-4 december 2007.

(2008). Italian and Australian local governments: balanced scorecard practices - A research note. Journal of Human Resource Costing \& Accounting 12 (1): 4-13.

Fassin, A. \& M. Buelens (2011). Small-Business Owner-Managers' Perceptions of Business Ethics and CSR-Related Concepts. Journal of Business Ethics 98 (3): 425-453.

Forrester Consulting (2007). The Total Economic Impact Of Microsoft Lync Server 2007. A Forrester Total Economic Impact ${ }^{\mathrm{TM}}$ Study Prepared For Microsoft. (Project Director: Jeffrey North, Principal Consultant). November 2007.

Freeman, E. R. \& J. A. F. Stoner (1992). Administração. Rio de Janeiro: Prentice Hall do Brasil. 
Gates, S. \& C. Germain (2010). Integrating sustainability measures into strategic performance measurement systems: An empirical study. Management Accounting Quarterly 19 (1): 1-7.

Gilbert, D. U., A. Rasche \& S. Waddock (2011). Accountability in a global economy: The emergence of international accountability standards. Business Ethics Quarterly 21 (1): 23-44.

Gonçalves, I. \& M. de S. Ribeiro (2011). Ética Empresarial e Responsabilidade Socioambiental: Um Estudo da Divulgação das Ações Ambientais Promovidas pelas Empresas do Agronegócio Brasileiro. XIII Congresso de Contabilidade e Auditoria - "A Change in Management", Porto, Portugal, 18 a 20 de Maio. ISCAP.

Guse, G. R., V. Avram, A. Calu, D. A. Calu \& M. Popescu (2010). Assets restatement model from the natural capital maintenance perspective. Internal Auditing and Risk Management Review 4 (20): 71-80.

Haider, H. (2010). Communication Initiatives to Change Attitudes and Behaviour. Helpdesk Research Report, Governance and Social Development Resource Centre, University of Birmingham. Disponível em: http://www.gsdrc.org/ docs/open/HD752.pdf

Harrington, H.J. \& A. Knight (2001). A implementação da ISO 14000: como actualizar o SGA com eficácia. São Paulo: Atlas.

Hasnaoui, A. \& I. Freeman (2010). Diffusion and Implementation of Corporate Social Responsibility (CSR): The Role of Information and Communication Technologies (ICT). Revue Management \& Avenir 37: 386-406.

(2011). The Meaning of Corporate Social Responsibility: The Vision of Four Nations. Journal of Business Ethics 2 (10): 15-30. DOI: 10.1007/ s10551-010-0688-6(cat 3 CNRS).

Husted, B. W. (2003). Governance choices for corporate Social Responsibility: to contribute, collaborate or internalize? Long Range Planning 36 (5): 481-498. 
\& D. B. Allen (2000). Is it ethical to use ethics as strategy? Journal of Business Ethics 27 (1-2): 21-31.

\& D. B. Allen (2001). Toward a Model of Corporate Social Strategy Formulation, Academy of Management 156.

Instituto Nacional de Estatística (2009). Rede de informação do INE em bibliotecas do ensino superior. Folha informativa da Ribess II. Disponível em: http://www.ine.pt ine.pt

(2011). Estatísticas do emprego 2011. Disponível em: http://www.

Instituto de Apoio às Pequenas e Médias Empresas (2005). Relatório de diagnóstico de identificação de práticas de responsabilidade social nas PME - Ser PME Responsável. Disponível em http://www.serpme.org/docs/diagonostico.pdf

Jamali, D. \& R. Mirshak (2007). Corporate Social Responsibility (CSR): theory and practice in a developing country context. Journal of Business Ethics 72 (3): 243-262.

Jonas, G. \& A. Jones (2010). Corporate Social Responsibility Reporting: Voluntary Disclosure Using Global Reporting Initiative Standards - Why? Journal of Business Ethics 30 (1): 97-112.

(2011). Corporate Social Responsibility Reporting: The Growing Need for Input from the Accounting Profession. CPA Journal 23: 89-104.

Kaplan, R. \& D. P. Norton (2004). Mapas Estratégicos. Barcelona: Gestión 2000.

Kavitha, W. \& Anita, P. (2011). Disclosures About CSR Practices: A Literature Review. The IUP Journal of Corporate Governance 10 (1): 45-57.

Kazazian, T. (2005a). Design e desenvolvimento sustentável. São Paulo: Senac. (2005b). Haverá a Idade das Coisas Leves. São Paulo: Senac. 
Laan, S. van der (2009). The Role of Theory in Explaining Motivation for Corporate Social Disclosures: Voluntary Disclosures vs 'Solicited' Disclosures. The Australasian Accounting Business \& Finance Journal 3 (4): 15-31.

Livro Verde (2001). Promover um quadro europeu para a responsabilidade social das empresas. 18 de Julho de 2001. Bruxelas: Comissão das Comunidades Europeias.

Logsdon, J. \& K. Yuthas (1997). Corporate social performance, stakeholder orientation and organizational moral development. Journal of Business Ethics 16 (12/13): 1213-1226.

Mancera, M. D. M. (2004). El informe anual y la responsabilidad social corporativa. X congresso de contabilidade - relato financeiro e Responsabilidade Social. Lisboa, 24 a 26 de novembro, Centro de estudos do Estoril.

Manzini, E. \& C. Vezzoli (2005). O desenvolvimento de produtos sustentáveis: os requisitos ambientais dos produtos industriais. São Paulo: Universidade de São Paulo.

C. Vezzoli \& G. Clark (2005). Product-Service Systems: Using an Existing Concept as a New Approach to Sustainability. UNEP DTIE Industry and Environment Review, Sustainable Consumtpion 22 (4): s.p.

Martínez, V. A., O. J. Boga, J. Orosa \& L. Rodríguez Campo (2005). Estrategias de comunicación en la gestión de la responsabilidad social de la empresa. Fisec-estrategias I (1): 23-46.

Meyssonnier, F. \& F. Rasolofo-Distler (2007). Le Controle De Gestion Entre Responsabilite Globale Et Performance Economique. Le Cas D'Une Entreprise Sociale Pour L'Habitat. Post-Print halshs HAL.

Monteiro, M. A. (2005). A Responsabilidade Social das Empresas (RSE). Cadernos do Mercado de Valores Mobiliários 21: 65-70.

Moral, A. M., R. Poyatos \& E. B. Jurado (2010). E-Corporate Social Responsibility in Andalusian agricultural cooperatives. Revista de Economía Pública, Social y Cooperativa 67: 187-212. 
Najmanovich, D. (2007). El desafío de la Complejidad: Redes, cartografías dinámicas y mundos implicados. Utopía y Praxis Latinoamericana 12 (38): 34-45.

Nascimento, I. C. (2010). Do capital Social ao Capital Económico das Grandes Empresas de Construção e Obras Públicas em Portugal. (Tese de doutoramento não publicada). Instituto superior de Economia e Gestão, Universidade Técnica de Lisboa.

Nicolau, I. \& A. Simaens (2008). O Impacto da Responsabilidade Social das Empresas nas Economia Social. Estudos-Revista Portuguesa e Brasileira de Gestão 6 (3): 78-94. Disponível em www.scielo.oces.mctes.pt/pdf/rpbg/ v7n1a08.pdf

(2009). The Evaluation of Social Solidarity Organization in the Portuguese Context. Methods and Indicators of Evaluation of the Entreprises and Organizations of the Social Economy 4: 54-63.

Oliveira, J. A. \& S. E. Chaves (2013). Responsabilidade social das organizações numa época de downsizing: responsabilidade social no apoio ao emprego. Leiria: Instituto Politécnico de Leiria-Escola Superior de Tecnologia e Gestão.

Pandey, I. M. (2005). Balanced Scorecard, Vikalpa. The Journal for Decision Makers 30 (1): 51-66.

Parecer De Iniciativa Sobre A Responsabilidade Social Das Empresas (2003). (Aprovado no Plenário de 17 de Janeiro de 2003). (Relator Conselheiro: Vitor Melícias). LISBOA.

Pérez, R. A. (2012). Pensar la estrategia. Buenos Aires: La Crujía Ediciones.

Qualidade de vida no trabalho: origem, evolução e perspectivas (2001). Cadernos de pesquisa em administração 8 (1).

Reich, R. B. (1998). The new meaning of corporate Social Responsibility. California Management Review 40 (2): 8-17.

Responsabilidade social das empresas: um pouco de história e algumas reflexões (2004). Revista FAE 9: 36-38. 
Ribeiro, M. de S. \& L. P. Lisboa (1999). Balanço Social. Revista Brasileira de Contabilidade 115: 72-81.

Ribeiro, M., A. Giuliani \& D. Corrêa (2006). Social responsibility in the retail: case petrobras distribuidora. XI Congresso Internacional de Contabilidade e Auditoria, Coimbra, 16-18 de novembro de 2006. ISCA.

Rivoli, P. \& S. Waddock (2011). First They Ignore You...: The Time Context Dynamic and Corporate Responsibility. California Management Review 53 (2): 78-91.

Sardinha, I. (s.d.). Responsabilidade Social nas Empresas: A sua Contribuição para o Desenvolvimento Sustentável. Disponível em http://pascal.iseg.utl. $\mathrm{pt} / \sim$ socius/publicacoes/wp/txtAPEA.pdf

Schadewitz, H. \& M. Niskala (2010). Communication Via Responsibility Reporting and Its Effect on Firm Value in Finland. Corporate Social Responsibility and Environmental Management 17 (2): 87-94.

Schwartz, M. \& A. Carroll (2003). Corporate Social Responsibility: a three-domain approach. Business Ethics Quarterly 13 (4): 503-530.

(2007). The Search for a Common Core in the Business and Society Field. Business Society 20 (10): 1-39.

(2008). Integrating and unifying competing and complementary frameworks. Business \& Society 47 (2): 148-186.

Serra, F. M. D. (2008). Redes sociales, pensamiento sistémico y dinámica de sistemas: aportes al estrategar y al comunicar. FISEC-Estrategias - Facultad de Ciencias Sociales de la Universidad Nacional de Lomas de Zamora 11: 149-168.

Smith, N. C. (2003). Corporate Social Responsibility. Whether or how? California Management Review 45 (4): 52-76.

Solomon, A. \& L. A. Lewis (2002). Incentives and disincentives for corporate environmental disclosure. Business Strategy and the Environment 11 (3): 154-169. 
Stoner, J. A. F. \& R. E. Freeman (1999). Administração. Rio de Janeiro: LTC.

Swanson, D. (1995). Addressing a theoretical problem by reorienting the corporate social performance model. Academy of Management Review 20 (1): 43-64.

(1999). Toward an integrative theory of business and society: a research strategy for corporate social performance. Academy of Management Review 24 (3): 506-521.

Tinoco, J. E. P. (2001). Balanço social: uma abordagem da transparência e da responsabilidade pública das organizações. São Paulo: Atlas.

Torres, Ciro (2002). Um pouco da história do Balanço Social. Disponível em: http://www.balancosocial.org.br/historico.htm

Tsuji, M. \& Y. Tsuji (2010). The impact of the International Financial Report Standards for mergers and acquisitions on potential employees: some Japanese evidence. Journal of International Business Research 9 (1): 78-90.

Uccello, C. (2009). Social Interest and Social Responsibility in Contemporary Corporate Environments. The Journal of Individual Psychology 65 (4): 412-421.

Waagstein, P. R. (2011). The Mandatory Corporate Social Responsibility in Indonesia: Problems and Implications. Journal of Business Ethics 98: 455-466.

Wartick, S. \& P. Cochran (1985). The evolution of the corporate social performance model. Academy of Management Review 10 (4): 758-769.

Windsor, D. (2001). The future of corporate Social Responsibility. The International Journal of Organizational Analysis 9 (3): 225-256.

Wood, D. J. (1991). Corporate social performance revisited. Academy of Management Review 16 (4): 691-718. 
